\title{
Taxation and Unemployment in Models with Heterogeneous Workers*
}

\author{
Marcus Hagedorn ${ }^{\dagger}$ \\ University of Oslo
}

\author{
Iourii Manovskii ${ }^{\ddagger}$ \\ University of Pennsylvania
}

\author{
Sergiy Stetsenko ${ }^{\S}$ \\ GM Financial
}

August 2015

\begin{abstract}
We introduce ex-ante heterogeneity between workers and two technology shocks, neutral and investment-specific, as the driving forces into the basic Mortensen-Pissarides search and matching model. The calibrated model is simultaneously consistent with a strong response of labor market variables to cyclical fluctuations in productivity and a weaker response to changes in taxes found in cross-country data. The model also matches the evidence that countries with higher tax rates have higher aggregate productivity, lower skill premia, and higher unemployment rates among both high- and low-skilled workers. The key mechanism that allows us to achieve these results is that aggregate and group-specific productivities are endogenous and respond to changes in tax policy.
\end{abstract}

JEL Classification: E24, E32, J63, J64, J68

Keywords: Search, Matching, Business Cycles, Heterogeneity, Labor Markets

${ }^{*}$ We would like to thank seminar participants at Boston University, the macro club meeting at the University of Pennsylvania, NBER Summer Institute and the Research on Money and Markets conference at the University of Toronto for useful comments. This research has been supported by the National Science Foundation Grants No. SES-0617876, SES-0922406 and SES-1357903.

${ }^{\dagger}$ University of Oslo, Department of Economics, Box 1095 Blindern, 0317 Oslo, Norway. Email: marcus.hagedorn07@gmail.com

${ }^{\ddagger}$ Department of Economics, University of Pennsylvania, 160 McNeil Building, 3718 Locust Walk, Philadelphia, PA, 19104-6297 USA. E-mail: manovski@econ.upenn.edu.

${ }^{\S}$ Assistant Vice President, Economic Analysis, GM Financial, Dallas/Fort Worth, TX, USA. 


\section{Introduction}

The facts describing the secular evolution of unemployment and taxes in the U.S. and continental Europe are well known. In the 1960s unemployment rates were quite similar in the U.S. and in the continental European countries. While the unemployment rate in the U.S. has remained at almost the same level at least until the Great Recession, the rates in many European countries have increased starting in the late 1970s and stayed considerably higher than in the U.S. since then. At the same time the tax wedge, measured as the sum of labor and sales taxes, has increased in those European countries relative to the U.S.

A natural framework to understand the relationship between taxes and unemployment is the leading theory of equilibrium unemployment, the Mortensen and Pissarides (MP) search and matching model. However, this simple framework has an important limitation for studying the effects of policies, such as taxation. Productivity is assumed to be exogenous so that it does not respond to changes in tax rates. This seems restrictive both from an empirical and a theoretical perspective. Empirically, Prescott (2004), among others, documents that the increase in tax rates was accompanied by an increase in aggregate productivity (most notably in France and Germany) relative to productivity in the U.S. Furthermore, we document that the skill premium, the relative productivity of college and high school graduates, is strongly negatively related to the tax wedge.

Theory also suggests that large differences in policy do not leave productivity unaffected. In the theory developed in Krusell, Ohanian, Ríos-Rull, and Violante (2000), changes in productivity are due to a technology which features capital-skill complementarity. ${ }^{1}$ The adjustment of the stocks of capital as well as of high- and low-skilled labor in response to a change in policy leads to an endogenous change in productivity. This theory is a natural candidate to conduct a quantitative analysis with because changes in productivity can be accounted for by changes in observed factor quantities, most notably the stock of capital equipment. Thus, building on the standard MP setup we allow for ex-ante heterogeneity in skills (high-skilled and low-skilled workers) that interact on the production side of the economy as in Krusell,

\footnotetext{
${ }^{1}$ The literature on induced technical change, e.g., Acemoglu (2002, 2007) predicts a non-neutral shift in productivity in response to the change in relative abundance of productive inputs. If, for example, unemployed low-skilled labor becomes more abundant due to a change in the tax policy, technologies that are biased toward low-skilled labor and thus increase its productivity are more likely to be developed in the long run.
} 
Ohanian, Ríos-Rull, and Violante (2000).

The endogenous response of productivity in our model has several important implications. First, in the standard MP model, a one percentage point permanent decrease in productivity and a one percentage point permanent increase in sales taxes increase unemployment by the same amount. The finding that these two responses are very close is not a coincidence but a feature of many models driven by productivity, including the MP model. However, the data suggest that the elasticity with respect to productivity necessary to replicate business cycles is larger than the elasticity with respect to taxes required to explain cross-country differences (Costain and Reiter, 2008; Mortensen and Nagypal, 2007; Hornstein, Krusell, and Violante, 2005b). ${ }^{2}$ Our framework can resolve this dilemma. The endogenous response of productivity mitigates the response to changes in tax policy without sacrificing the business cycle properties.

Second, Hornstein, Krusell, and Violante (2005a) have pointed out that the MP model has the counterfactual implication that the rise in unemployment in response to, e.g., skill-biased technical change is concentrated among the low-skilled workers ${ }^{3}$, whereas Nickell and Bell (1996) and Gottschalk and Smeeding (1997), among others, conclude that data from many European countries support the conclusion that unemployment rose proportionately across the entire skill spectrum. We show that the change in productivities in our model induced by an increase in the tax wedge shifts the rise in unemployment toward high skilled workers.

We calibrate the model following the strategy of Hagedorn and Manovskii (2008a) and find that the two-skill version of the MP model is consistent with the cyclical volatility of the aggregate and group-specific labor market variables in the data. The model generates a high unemployment volatility among low-skilled workers because their productivity in the market is estimated to be relatively close to their productivity at home. The model also matches a high volatility of unemployment among high skilled workers despite the fact that their estimated value of non-market activity is substantially lower than their market productivity. ${ }^{4}$

\footnotetext{
${ }^{2}$ For example, the MP model calibrated in Hagedorn and Manovskii (2008a) generates the observed amount of volatility of unemployment and vacancies but generates very large policy effects.

${ }^{3}$ See, for example, Mortensen and Pissarides (1999) and Albrecht and Vroman (2002) for alternative models that share this prediction.

${ }^{4}$ This is consistent with the common prior articulated in e.g., Mortensen and Pissarides (1999) who argue that it is a "plausible assumption that the economic value of non-employment (other than UI benefits) does not increase proportionately with skill." Moreover, they argue that the same is true of the UI benefits which are closer to the productivity level of less skilled workers.
} 
To understand the cyclical behavior of labor market variables for different groups of workers it is essential to identify the cyclical behavior of their productivities. ${ }^{5}$ The aggregate production function estimated by Krusell, Ohanian, Ríos-Rull, and Violante (2000) provides the way to do so. This production function accounts exceptionally well for the trends in wages of skilled and unskilled workers over the last several decades. It thus appears to be a natural candidate to provide an accurate and parsimonious way to also measure the business-cycle properties of the marginal productivities of the two labor inputs it considers: high-skilled and low-skilled workers. Measuring the evolution of worker productivity using this production function, we find that the (endogenously determined) marginal product of high-skilled workers is considerably more volatile over the business cycle than the marginal product of low-skilled workers. One important reason for this finding is that Krusell, Ohanian, Ríos-Rull, and Violante (2000) estimate that high-skilled workers and capital equipment are complements in the production process. Since investment-specific shocks are an important contributor to business cycle fluctuations (Fisher, 2006), they amplify the volatility of productivity of high-skilled workers. This explains why the cyclical volatility of unemployment is high for high-skilled workers despite them having a relatively low value of non-market activities. We also note that without capital-skill complementarities the effects of investment-specific shocks would be much smaller since they would not be focused on one group.

The paper is organized as follows. A discrete time stochastic version of the Pissarides (1985, 2000) search and matching model with two skill groups and capital-skill complementarity is laid out in Section 2. In Section 3 we develop our calibration strategy. In Section 4 we describe the quantitative behavior of the model over the business cycle, both in the aggregate and for both groups of workers. We find that the model matches the cyclical volatility of labor market variables very well. A comparison with the results from the homogeneous worker model (with exogenous productivity) implies that the model with worker heterogeneity generates higher volatility of aggregate labor market statistics and is closer to the data than the homogeneous worker model.

\footnotetext{
${ }^{5}$ We cannot use wages to infer the cyclical behavior of productivity because wages are not equal to the marginal product of labor in a search model. In most parameterizations of the MP model, including the one in this paper, the level of wages is very close to average productivity. The cyclical properties of wages, however, are different from the cyclical properties of productivity.
} 
Having verified that the model is a good quantitative laboratory, we conduct the analysis of the effects of tax policies in Section 5. The analysis is subdivided in two parts. First, we analyze the effects of policies theoretically to better understand how the model works and what features of the model are important for dampening the effects of policies. One important result is that introducing curvature in the production side of the MP model is not sufficient per se to dampen the effects of policies. It is only if the production function includes heterogeneous and imperfectly substitutable labor inputs that the effects of policies will be dampened relative to the effects of cyclical movements in productivity. Next, we use the calibrated model to evaluate the effects of policies quantitatively. We find that the effects of policies are dampened substantially compared to the homogeneous agent version of the model, and are in line with the effects of policies implied by the data. Moreover, consistent with the U.S. and European experiences, higher taxes increase the productivity of low skilled workers and (slightly) decrease the productivity of high skilled workers, so that aggregate productivity increases and the skill premium decreases. The relative change in productivities also shifts the rise in unemployment toward high skilled workers. Since the productivity of low skilled workers increases in equilibrium, firms incentives to post vacancies for low skilled workers increase and this lowers their unemployment rate whereas for high skilled workers the opposite holds. Section 6 concludes.

\section{The Model}

We consider a stochastic discrete time version of the Pissarides $(1985,2000)$ search and matching model with aggregate uncertainty and workers of two types $T \in\{L, H\}$, referring to lowand high-skilled workers, respectively.

\subsection{Workers and Firms}

There are measures $N^{T}$ of infinitely lived workers of each type and a continuum of infinitely lived firms. Workers maximize their expected lifetime utility:

$$
\mathbb{E} \sum_{t=0}^{\infty} \delta^{t} y_{t}^{T},
$$


where $y_{t}^{T}$ represents income in period $t$ and $\delta \in(0,1)$ is workers' and firms' common discount factor.

There is a competitive final goods sector that combines 4 inputs - low-skilled labor $l_{t}$, high-skilled labor $h_{t}$, capital structures $k_{s t}$ and capital equipment $k_{e t}$ - to produce the final good through the following production function (Krusell, Ohanian, Ríos-Rull, and Violante, 2000):

$$
y_{t}=F\left(l_{t}, h_{t}, k_{s t}, k_{e t}\right)=A_{t} k_{s t}^{\alpha}\left[\mu l_{t}^{\sigma}+(1-\mu)\left(\lambda k_{e t}^{\rho}+(1-\lambda) h_{t}^{\rho}\right)^{\frac{\sigma}{\rho}}\right]^{\frac{1-\alpha}{\sigma}},
$$

where $A_{t}$ is a neutral technology shock.

The resource constraint is ${ }^{6}$

$$
F(t)=C_{t}+i_{s t}+\frac{i_{e t}}{q_{t}}
$$

where $i_{s t}$ is investment in capital structures, $i_{e t}$ is investment in capital equipment, $C_{t}$ is consumption, and where the technology parameter $q_{t}$ determines the amount of equipment that can be produced by one unit of final output. In a perfectly competitive market, $q_{t}$ is also the relative price between consumption and equipment, a feature we exploit to measure $q$ in the calibration (as in Greenwood, Hercowitz, and Krusell, 1997; Krusell, Ohanian, Ríos-Rull, and Violante, 2000). The two stocks of capital evolve according to the following dynamic equations:

$$
\begin{aligned}
& k_{s, t+1}=\left(1-d_{s}\right) k_{s t}+i_{s t} \\
& k_{e, t+1}=\left(1-d_{e}\right) k_{e t}+i_{e t}
\end{aligned}
$$

where $d_{e}$ and $d_{s}$ are the depreciation rates of capital equipment and capital structures respectively.

Both $A_{t}$ and $q_{t}$ are assumed to follow $\mathrm{AR}(1)$ processes,

$$
\begin{aligned}
\log A_{t} & =\bar{A}+\kappa_{A} \log A_{t-1}+\epsilon_{A, t} \\
\log q_{t} & =\bar{q}+\kappa_{q} \log q_{t-1}+\epsilon_{q, t} .
\end{aligned}
$$

The two shocks, $\epsilon_{A, t}$ and $\epsilon_{q, t}$ are independent normal variables with respective standard deviations $\eta_{A}$ and $\eta_{q}$.

\footnotetext{
${ }^{6}$ To keep the notation concise, we occasionally specify $t$ as the only argument of a function, meaning that the function depends on a time $t$ vector of arguments. For example, $F(t) \equiv F\left(l_{t}, h_{t}, k_{s t}, k_{e t}\right)$.
} 
Each firm operating in the intermediate goods sector is either matched with an unskilled worker, matched with a skilled worker or posts a vacancy. If matched, it receives, from the competitive final sector, $p_{t}^{L}=F_{l}(t)$ or $p_{t}^{H}=F_{h}(t)$. There is free entry of firms. Firms attract unemployed workers by posting a vacancy at the flow cost $c^{T}$. Once matched, workers and firms separate exogenously with probability $s^{T}$ per period. Employed workers are paid a wage $w_{t}^{T}$, and firms make accounting profits of $p_{t}^{T}-w_{t}^{T}$ per worker each period in which they operate. Unemployed workers get flow utility $z^{T}$ from leisure/non-market activity.

\subsection{Matching}

Let $u_{t}^{T}$ denote the number of unemployed and $n_{t}^{T}=N^{T}-u_{t}^{T}$ the number of employed individuals from group $T\left(n^{L}=l\right.$ and $\left.n^{H}=h\right)$. Let $v_{t}^{T}$ be the number of vacancies posted in period $t$. We refer to $\theta_{t}^{T}=v_{t}^{T} / u_{t}^{T}$ as the market tightness at time $t$ for type $T$. The aggregate market tightness is defined as $\theta_{t}=\left(v_{t}^{H}+v_{t}^{L}\right) /\left(u_{t}^{H}+u_{t}^{L}\right)$.

The number of new matches (starting to produce output at $t+1$ ) is given by a constant returns to scale matching function $m^{T}\left(u_{t}^{T}, v_{t}^{T}\right) \leq \min \left(u_{t}^{T}, v_{t}^{T}\right)$. Employment evolves according to the following law of motion:

$$
n_{t+1}^{T}=\left(1-s^{T}\right) n_{t}^{T}+m^{T}\left(u_{t}^{T}, v_{t}^{T}\right) .
$$

The probability that an unemployed worker will be matched with a vacancy next period equals $f^{T}\left(\theta_{t}^{T}\right)=m^{T}\left(u_{t}^{T}, v_{t}^{T}\right) / u_{t}^{T}=m^{T}\left(1, \theta_{t}^{T}\right)$. The probability that a vacancy will be filled next period equals $\phi^{T}\left(\theta_{t}^{T}\right)=m^{T}\left(u_{t}^{T}, v_{t}^{T}\right) / v_{t}^{T}=m^{T}\left(1 / \theta_{t}^{T}, 1\right)=f^{T}\left(\theta_{t}^{T}\right) / \theta_{t}^{T}$.

\subsection{Equilibrium}

Denote the firm's value of a job (a filled vacancy) by $J^{T}$, the firm's value of an unfilled vacancy by $V^{T}$, the worker's value of having a job by $W^{T}$, and the worker's value of being unemployed by $U^{T}$. Bellman equations (9)-(12) describe an equilibrium of the model where $J^{T}, W^{T}, U^{T}$ and $V^{T}$ depend on the current shocks to productivity $A_{t}$ and $q_{t}$ and the stock of low-skilled $l_{t}$ and the stock of high-skilled $h_{t}$. Let $x_{t}=\left(A_{t}, q_{t}, l_{t}, h_{t}\right)$ be today's state vector and $x_{t+1}=\left(A_{t+1}, q_{t+1}, l_{t+1}, h_{t+1}\right)$ be next period's state vector. The two capital stocks $k_{e}$ and $k_{s}$ do not have to be included in the state vector, since risk neutrality implies that they are 
already functions of $x .^{7}$

$$
\begin{aligned}
J_{x_{t}}^{T} & =p_{x_{t}}^{T}-w_{x_{t}}^{T}+\delta\left(1-s^{T}\right) E_{x_{t}} J_{x_{t+1}}^{T} \\
V_{x_{t}}^{T} & =-c^{T}+\delta \phi^{T}\left(\theta_{x_{t}}^{T}\right) E_{x_{t}} J_{x_{t+1}}^{T} \\
U_{x_{t}}^{T} & =z_{t}^{T}+\delta\left\{f^{T}\left(\theta_{x_{t}}^{T}\right) E_{x_{t}} W_{x_{t+1}}^{T}+\left(1-f^{T}\left(\theta_{x_{t}}^{T}\right)\right) E_{x_{t}} U_{x_{t+1}}^{T}\right\} \\
W_{x_{t}}^{T} & =w_{x_{t}}^{T}+\delta\left\{\left(1-s^{T}\right) E_{x_{t}} W_{x_{t+1}}^{T}+s^{T} E_{x_{t}} U_{x_{t+1}}^{T}\right\} .
\end{aligned}
$$

The interpretation is straightforward. Operating firms earn profits $p_{x_{t}}^{T}-w_{x_{t}}^{T}$ and the matches are exogenously destroyed with probability $s^{T}$. A vacancy costs $c^{T}$ and is matched with a worker (becomes productive in period $t+1$ ) with probability $\phi^{T}\left(\theta_{x_{t}}^{T}\right)$. An unemployed worker derives utility $z^{T}$ and finds a job next period with probability $f^{T}\left(\theta_{x_{t}}^{T}\right)$. An employed worker earns wage $w_{x_{t}}^{T}$ but may lose her job with probability $s^{T}$ and become unemployed next period. Nash bargaining implies that a worker and a firm split the surplus $S_{x_{t}}^{T}=J_{x_{t}}^{T}+W_{x_{t}}^{T}-U_{x_{t}}^{T}$ such that

$$
\begin{gathered}
J_{x_{t}}^{T}=\left(1-\beta^{T}\right) S_{x_{t}}^{T}, \\
W_{x_{t}}^{T}-U_{x_{t}}^{T}=\beta^{T} S_{x_{t}}^{T} .
\end{gathered}
$$

Free entry implies that the value of posting a vacancy is zero: $V_{x_{t}}^{T}=0$ for all $x_{t}$ and, therefore,

$$
\begin{aligned}
c^{T} & =\delta \phi^{T}\left(\theta_{x_{t}}^{T}\right) E_{x_{t}} J_{x_{t+1}}^{T} \\
& =\delta \phi^{T}\left(\theta_{x_{t}}^{T}\right)\left(1-\beta^{T}\right) E_{x_{t}} S_{x_{t+1}}^{T}
\end{aligned}
$$

The Bellman equation for the surplus is:

$$
S_{x_{t}}^{T}=p_{x_{t}}^{T}-\left(z^{T}+\delta f^{T}\left(\theta_{x_{t}}^{T}\right) \beta^{T} E_{x_{t}} S_{x_{t+1}}^{T}\right)+\delta\left(1-s^{T}\right) E_{x_{t}}^{T} S_{x_{t+1}}^{T}
$$

To compute expectations, one has to know how the state variables evolve. The two productivity processes evolve according to the $\operatorname{VAR}(1)$ described above. The value of marginal productivity $p^{T}$ next period is endogenous and depends on how many workers are working today, how many vacancies are posted and how much capital is invested.

\footnotetext{
${ }^{7}$ The two first-order conditions for capital equipment and capital structures describe period $t$ capital stocks as functions of $x_{t}$ only because risk neutrality implies that the real interest rate is constant. Without risk neutrality this simplification would not be possible, since the period $t$ interest rate would depend on consumption in period $t$ and $t+1$.
} 
The market for capital equipment and structures is perfectly competitive and, each period, firms can rent capital to maximize profits. Households own the capital stock and invest to maximize their utility, which leads to the two first-order conditions for capital: ${ }^{8}$

$$
\begin{aligned}
E_{t} F_{k_{s}}(t+1)+\left(1-d_{s}\right) & =\frac{1}{\delta}, \\
q_{t} E_{t} F_{k_{e}}(t+1)+\left(1-d_{e}\right) E_{t} \frac{q_{t}}{q_{t+1}} & =\frac{1}{\delta} .
\end{aligned}
$$

Note, that the decision on $k_{e, t+1}$ is taken in period $t$, but that the relative price of investment goods next period, $q_{t+1}$, matters for this decision as well.

We now derive the expressions for equilibrium wages and profits, which, except for being dependent on the type, take the usual form. ${ }^{9}$ Because firms can buy and sell capital in a competitive market, the wage bargain is not affected as in Pissarides (2000). Using equation (13), it follows from the free-entry condition (15) and the flow equation (9) for $J^{T}$ that:

$$
\left(1-\beta^{T}\right) S_{x_{t}}^{T}=p_{x_{t}}^{T}-w_{x_{t}}^{T}+\left(1-s^{T}\right) c^{T} / \phi^{T}\left(\theta_{x_{t}}^{T}\right)
$$

Free entry and (16) imply that

$$
S_{x_{t}}^{T}=p_{x_{t}}^{T}-z^{T}+\left(1-s^{T}-f^{T}\left(\theta_{x_{t}}^{T}\right) \beta\right) \frac{c^{T}}{\phi^{T}\left(\theta_{x_{t}}^{T}\right)\left(1-\beta^{T}\right)} .
$$

Thus, we have that

$$
\left(1-\beta^{T}\right) S_{x_{t}}^{T}=\left(1-\beta^{T}\right)\left(p_{x_{t}}^{T}-z^{T}\right)+c^{T} \frac{1-s^{T}-f^{T}\left(\theta_{x_{t}}^{T}\right) \beta^{T}}{\phi^{T}\left(\theta_{x_{t}}^{T}\right)} .
$$

Rearranging (19) and substituting using (21), we find that wages are given by

$$
\begin{aligned}
w_{x_{t}}^{T} & =p_{x_{t}}^{T}-\left(1-\beta^{T}\right) S_{x_{t}}^{T}+\left(1-s^{T}\right) c^{T} / \phi^{T}\left(\theta_{x_{t}}^{T}\right) \\
& =\beta^{T} p_{x_{t}}^{T}+\left(1-\beta^{T}\right) z^{T}+c^{T} \beta^{T} \theta_{x_{t}}^{T}
\end{aligned}
$$

and accounting profits are given by

$$
\Pi_{x_{t}}^{T}=p_{x_{t}}^{T}-w_{x_{t}}^{T}=\left(1-\beta^{T}\right)\left(p_{x_{t}}^{T}-z^{T}\right)-c^{T} \beta^{T} \theta_{x_{t}}^{T} .
$$

${ }^{8}$ To see the second equation note that the $k_{e, t+1}$ is chosen to maximize $\ldots-\frac{k_{e, t+1}}{q_{t}}+\delta E_{t}\left(r_{t+1} k_{e, t+1}+\right.$ $\left.\frac{\left(1-d_{e}\right) k_{e, t+1}}{q_{t+1}}\right)+\ldots$, where $r=F_{k_{e}}$ is the interest rate in the rental market.

${ }^{9}$ It is well known that only the present value of wages and not the specific sequence of wages matters. We adopt here the standard assumption of Nash bargaining to pin down this sequence. Hagedorn and Manovskii (2013) provide evidence that this assumption is more consistent with the data than the alternative based on contracts through which firms insure workers against aggregate shocks. 


\section{Calibration}

In this section we calibrate the model to match U.S. labor market facts. We define the variables consistently with Krusell, Ohanian, Ríos-Rull, and Violante (2000) and conduct a measurement that ensures the comparability of our results to the large body of existing work on the cyclical behavior of unemployment and vacancies. ${ }^{10}$ In particular, we measure capital structures and equipment, output and employment in the non-farm business sector. As in Krusell, Ohanian, Ríos-Rull, and Violante (2000), the sample is restricted to individuals between 16 and 70 years old. The unskilled category includes individuals who have a high school diploma or less. The skilled category includes college-educated workers. Labor market data for the two subgroups comes from the monthly Current Population Surveys (CPS) from January 1976 to December 2006 and the CPS Outgoing Rotation Groups (ORG) covering the period January 1979 to December 2006. To aggregate individual observations we use CPS sample weights. On average over the sample period there are 2.6379 unskilled workers for each skilled worker. Whenever we are interested in cyclical properties of a variable observed at quarterly frequency, we use the HP-filter (Prescott, 1986) with a smoothing parameter of 1600 . The data and variable construction procedures we use are detailed in Appendix I.

Basics. We choose the model period to be one week (one-twelfth of a quarter), which is lower than the frequency of the employment data we use, but necessary to deal with time aggregation. The data used to compute some of the targets have monthly, quarterly or annual frequency, and we aggregate the model appropriately when matching those targets. We set $\delta=0.99^{1 / 12}$.

Job-Finding and Separation Rates. Using the CPS, we estimate, using the Shimer (2005b) two-state model described in Appendix I, the average monthly job-finding rate to be 0.3618 for skilled workers and 0.4185 for unskilled workers. The total separation rate (into unemployment, non-employment and job-to-job), not adjusted for time aggregation, for high-skilled equals 0.042 and for low-skilled 0.064 (Fallick and Fleischman, 2004). The separation rate

\footnotetext{
${ }^{10}$ As shown in Hagedorn and Manovskii (2008a), the results do not depend on whether the calibration includes taxation or not. However the efficiency properties of the model change. Without including taxation the model suggest large inefficiencies (too many vacancies and too low unemployment) whereas taking into account taxation implies that the decentralized economy is close to being efficient.
} 
into unemployment, also not adjusted for time aggregation, equals 0.0097 for the skilled and 0.0378 for the unskilled. We make this distinction between the rates of total separation and separation into unemployment, since what matters for firms' decisions is the expected duration of an employment spell, and this duration depends on the total rate of separation. We use this separation rate when modeling firms' decisions. To describe the average level and the evolution of unemployment for the two groups (Equation 8) we use the separation rate into unemployment only.

At a weekly frequency these estimates imply job-finding rates of $f^{H}=0.1062$ and $f^{L}=$ 0.1268 , total job separation rates of $s^{H}=0.0105$ and $s^{L}=0.016$, rates of separation into unemployment $s_{U}^{H}=0.0029$ and $s_{U}^{L}=0.0117$, and steady state unemployment rates of $u^{H}=$ $s_{U}^{H} /\left(s_{U}^{H}+f^{H}\right)=0.0262$ and $u^{L}=s_{U}^{L} /\left(s_{U}^{L}+f^{L}\right)=0.0846 .{ }^{11}$ These steady state unemployment rates are very similar to the average unemployment rate in the data of 0.0263 for skilled workers and 0.0838 for unskilled ones. ${ }^{12}$ Petronglo and Pissarides (2001) survey the empirical evidence and conclude that the value of 0.5 for the elasticity of the aggregate job-finding rate with respect to aggregate labor market tightness is appropriate. By skill group, we find that the elasticity of the job-finding probability with respect to overall labor market tightness is higher for high-skilled workers by a factor of 1.3345 .

Production Function Parameters. We use the elasticity parameters of the production function $\alpha=0.117, \sigma=0.401$, and $\rho=-0.495$ and weekly depreciation rates of structures and equipment $d_{s}=0.001068$ and $d_{e}=0.002778$ estimated by Krusell, Ohanian, Ríos-Rull,

\footnotetext{
${ }^{11}$ We now illustrate this adjustment procedure in the case of skilled workers. The probability of not finding a job within a month is $1-0.3603=0.6382$. The probability of not finding a job within a week then equals $0.6382^{1 / 4}=0.8938$ and the probability of finding a job equals $1-0.8938=0.1062$. The probability of observing someone not having a job who had a job one month ago equals (counting paths in a probability tree): $s\left\{(1-f)\left(f s+(1-f)^{2}\right)+f(s(1-f)+(1-s) s)\right\}+(1-s)\left\{s\left(f s+(1-f)^{2}\right)+(1-s)(s(1-f)+(1-s) s)\right\}=0.0097$. Solving for $s$, we obtain $s=0.0029$.

The total separation rate does not have to be adjusted for time aggregation, since it does not matter whether a worker switches employers once or multiple times between observation points. All we need to know is that the previous employment relationship ended.

${ }^{12}$ Those workers who get separated from firms but do not become unemployed can be thought of as being hired by a large firm or by the government. This hiring presumably involves no search frictions due to the sheer size of these employers. These large firms hire at a constant rate $s^{T}-s_{U}^{T}$, pay the same wage as other firms and workers get separated at rate $s_{U}^{T}$ into unemployment. Since workers receive the same wage in both type of firms, the Nash bargaining solution does not have to be modified.
} 
and Violante (2000). Given the values of these parameters and the average employment levels of high- and low-skilled workers, we normalize the average stock of capital structures, $k_{s}=$ 399.7251, capital equipment, $k_{e}=389.8385$, and aggregate productivity $A=0.4197$, and find the distribution parameters $\lambda=0.9341$ and $\mu=.7445$ as solutions to a system of five equations. The system includes the first-order conditions (17) and (18) for structures and equipment, the normalization that the marginal product of low-skilled labor is equal to 1 , the condition that the labor share is $2 / 3$ of output, and the condition that the ratio of the marginal products of skilled and unskilled workers is equal to 1.9846 , on average. ${ }^{13}$

The productivity of the two labor inputs is affected by the volatility of capital structures and equipment over the business cycle. In the data, the standard deviation of HP-filtered log capital structures is 0.0028 and the standard deviation of HP-filtered log quality-adjusted capital equipment is 0.0100 (see Appendix I). To ensure that the model matches the cyclical volatility of the capital series, we allow the depreciation rates for capital structures and equipment to depend on aggregate productivity. In particular, we introduce and calibrate a parameter $d_{e}^{*}$ and specify the depreciation of capital equipment at time $t$ to equal $d_{e} *\left(k_{e, t} / \bar{k}_{e}\right)^{*}$. Thus, if equilibrium capital equipment stock $k_{e, t}$ in period $t$ is equal to the average capital equipment $\bar{k}_{e}$, the depreciation rate is given by $d_{e}$. If capital in some periods deviates from its steady state value, the depreciation rate deviates in the same direction. The strength of the response of the depreciation rate is governed by parameter $d_{e}^{*}$. The depreciation rate for capital structures is defined symmetrically with parameters $d_{s}$ and $d_{s}^{*}$. ${ }^{14}$

\footnotetext{
${ }^{13}$ The last target is consistent with the competitive model but may not hold exactly in the model with search frictions. This theoretical inconsistency has a negligible impact on our findings because, in our calibration, the average wage is close to the marginal product.

${ }^{14}$ Our motivation for adding variable depreciation rates is to generate the right volatilities of the two capital stocks. Alternatively we could treat the capital stocks as exogenous and just calibrate the two processes. This approach would leave our quantitative analysis unchanged. However, this approach is unattractive when performing policy experiments, since the capital stock responds to changes in taxation in our environment and the analysis will neglect this response if capital is modeled as being exogenous. We experimented with several alternative ways of adding capital to the model without significant impact on the results. We thus settled on the the most convenient one. Departing from linear utility would also reduce the volatility of capital and capital would be an endogenous variable. However, the data imply an asymmetric adjustment of the volatilities of the two capital stocks whereas a departure from linear utility would presumably lead to a symmetric reduction. Non-linear utility would also endogenize the real interest rate, leaving the volatilities of the key labor market variables however largely unaffected. Policy experiments are not affected at all since we compare steady states which all have the same real interest rate.
} 
Neutral and Capital Equipment-Specific Technologies. We use the estimated production function parameters and compute the quarterly series for $A_{t}$ and $q_{t}$. We set $q_{t}$ equal to the NIPA price of consumption goods (non-durables and services), $p_{t}^{c}$, divided by the price of equipment investment goods, $p_{t}^{e}$. We use the $p_{t}^{e}$ series constructed by Schorfheide, Rios-Rull, Fuentes-Albero, Santaeulalia-Llopis, and Kryshko (2012). (They extend the annual series of Cummins and Violante (2002) to 2006 and convert the annual series to quarterly frequency similar to Fisher (2006)). We use the resulting price series to construct the quality-adjusted stock of capital equipment using the perpetual inventory method. $A_{t}$ is then measured as Solow residual (see Appendix I.3).

We log and linearly de-trend the $A_{t}$ and $q_{t}$ series and use the resulting series to estimate the VAR in (6) and (7). To calibrate this process in the model, we consider quarterly averages of weekly productivity. We find that at weekly frequency we must set $\kappa_{A}=0.9936, \kappa_{q}=0.9988$, $\eta_{A}=0.0035$, and $\eta_{q}=0.0019$ to match the process in the data. We also normalize the average $\bar{q}=1$ and the average productivity of an unskilled worker equal to one, which requires setting $\bar{A}=.4197$.

Labor Market Tightness. Hagedorn and Manovskii (2008a) estimate an average value of labor market tightness of 0.634 . This value lies between the estimates of 0.539 obtained by Hall (2005) and 0.72 obtained by Pissarides (2009).

In Hagedorn and Manovskii (2008a) we used data on the time and costs involved in recruiting workers from the 1982 Employment Opportunity Pilot Project survey and the 1992 Small Business Administration survey reported in Barron, Berger, and Black (1997). These authors also estimate the vacancy duration equation $D=c_{0}+c_{1} X$ using the same datasets, where $D$ is the log of the duration time and $X$ is the set of controls including the log number of years of education, and report that the education coefficient is statistically significant in both datasets and equal to 0.886 and 2.432, respectively. The average years of education in our sample for high-skilled and low-skilled workers are equal to $e d^{H}=16.54$ and $e d^{L}=10.83$, respectively. This implies that vacancies for high skilled workers last $d^{r e l}=\left(e d^{H} / e d^{L}\right)^{c_{1}}=2.128$ times longer, where the actual number represents the average across the two data sets. The ratio of the market tightnesses across groups is then given by $\theta^{r e l}=f^{H} / f^{L} * d^{r e l}=1.78$. Finally, using the data on the numbers of skilled and unskilled unemployed workers, the aggregate $\theta$, 
and the relative $\theta^{\text {rel }}$ of high skilled workers we obtain that $\theta^{L}=0.5858$ and $\theta^{H}=1.0442$.

Matching Functions. We choose the Cobb-Douglas functional form of the matching functions of skilled and unskilled workers:

$$
m\left(u^{T}, v^{T}\right)=\chi^{T}\left(u^{T}\right)^{\gamma^{T}}\left(v^{T}\right)^{1-\gamma^{T}} .
$$

The two parameters, $\chi^{T}, \gamma^{T}$, that characterize the matching function differ for the two types. This allows us to match a different job-finding probability and a different elasticity of the job-finding probability with respect to labor market tightness.

The Cyclicality of Wages. Over the 1979:1-2006:4 period we find that a 1-percentage-point increase in labor productivity is associated with a 0.674 -percentage-point increase in average real wages. Wages are measured as the non-farm business labor share constructed by the BLS times labor productivity defined as seasonally adjusted real non-farm business output constructed by the BLS from the NIPA divided by seasonally adjusted non-farm business employment form the monthly Current Population Survey. Both time series are in logs and HP-detrended. We also use CPS data to estimate the wage elasticity with respect to average output per person for each group separately. We find that wages for high-skilled workers are more cyclical than wages of low-skilled. The ratio of the two elasticities equals 1.771. The estimates reported in Castro and Coen-Pirani (2008) imply a very similar ratio of wage elasticities. To obtain the corresponding estimates in the model, we first aggregate the weekly model-generated data to replicate the quarterly frequency of the data. We then log and HPfilter the time series and estimate regressions identical to those estimated in the data. ${ }^{15}$

The Costs of Posting Vacancies. In Hagedorn and Manovskii (2008a) we found that the

\footnotetext{
${ }^{15}$ Keane and Prasad (1991) and Prasad (1996) report, using NLSY from 1966-1981, similar magnitudes for the cyclicality of wages of skilled and unskilled workers. We replicated their analysis using the NLSY 1979 data (over the 1979:1-2006:4 period that corresponds to the coverage of the CPS data we use). See Hagedorn and Manovskii (2013) for a detailed description of NLSY 1979 and the variable construction procedures. We found a ratio of the wage elasticities for high and low skilled workers that is remarkably close to the number we computed based on the CPS data. These findings suggest that the properties of wages shifted in the early 1980s. This is also consistent with the finding of Parker and Vissing-Jorgensen (2009), who report that the relative volatility of labor income of high earners (likely correlated with being more educated) increased sharply around the early $1980 \mathrm{~s}$.
} 
expected labor costs of posting vacancies equals $50.23 \%$ of average weekly labor productivity. The flow capital costs of posting vacancies equals $47.4 \%$ of average weekly labor productivity, which equals 1.2707 , so that the capital costs equal 0.6023 . The analysis from Hagedorn and Manovskii (2008a) for these average numbers applies here as well. However, the presence of capital-skill complementarity and two types of capital implies that the numbers for the two groups are different.

For labor costs it is simple. We find that the skill premium in the data equals 1.9846. The expected costs of a vacancy in the model equals $\frac{c_{W}^{T}}{\phi^{T}}$, where $c_{W}^{T}$ is the flow cost and $\phi^{T}$ is the probability of filling a vacancy. The numbers we report above imply that $\phi^{H}=0.1017$ and $\phi^{L}=0.2165$. Solving $\frac{c_{W}^{L}}{\phi^{L}}=0.5023$ and $\frac{c_{W}^{H}}{\phi^{H}}=1.9846 \cdot 0.5023$, we find $c_{W}^{H}=0.1014$ and $c_{W}^{L}=0.1087$.

The specification of the production function in Krusell, Ohanian, Ríos-Rull, and Violante (2000) features capital-skill complementarity, so that more capital is bought when a highskilled worker is hired than when a low-skilled worker is hired. The relative sizes of capital equipment and capital structures needed can be computed from the first-order conditions (17) and (18). For skilled workers, the implicit function theorem provides us with two functions $k_{s}(h)$ and $k_{e}(h)$ solving the two first-order conditions, keeping the number of unskilled workers fixed. Analogously for unskilled workers, we get two functions $k_{s}(l)$ and $k_{e}(l)$. The relative capital needs for capital equipment then equals $\frac{\frac{\partial k_{e}(h)}{\partial h}}{\frac{\partial k_{e}(l)}{\partial l}}$ and the relative capital needs for capital structures equals $\frac{\frac{\partial k_{s}(h)}{\partial h}}{\frac{\partial k_{s}(l)}{\partial l}}$. Evaluating these expressions at the steady state gives $\frac{\frac{\partial k_{e}(h)}{\partial h}}{\frac{\partial k_{e}(l)}{\partial l}}=8.3384$ and $\frac{\frac{\partial k_{s}(h)}{\partial h}}{\frac{\partial k_{s}(l)}{\partial l}}=1.9846$.

We can now compute the flow capital costs for high-skilled $c_{e}^{H}$ (for equipment) and $c_{s}^{H}$ (for structures) and for low skilled: $c_{e}^{L}$ (for equipment) and $c_{s}^{L}$ (for structures). The different capital needs imply that $c_{e}^{H}=8.3384 c_{e}^{L}$ and $c_{s}^{H}=1.9846 c_{s}^{L}$.

The average flow cost for equipment equals $c_{e}^{H} \frac{v^{H}}{v^{H}+v^{L}}+c_{e}^{L} \frac{v^{L}}{v^{H}+v^{L}}$ and that for structures equals $c_{s}^{H} \frac{v^{H}}{v^{H}+v^{L}}+c_{s}^{L} \frac{v^{L}}{v^{H}+v^{L}}$. Since the capital income share for structures equals 0.117 and that for equipment equals $(1 / 3-0.117)$ we solve

$$
\begin{aligned}
c_{e}^{H} \frac{v^{H}}{v^{H}+v^{L}}+c_{e}^{L} \frac{v^{L}}{v^{H}+v^{L}} & =\frac{1 / 3-0.117}{2 / 3} 0.6023 \\
c_{s}^{H} \frac{v^{H}}{v^{H}+v^{L}}+c_{s}^{L} \frac{v^{L}}{v^{H}+v^{L}} & =\frac{0.117}{1 / 3} 0.6023
\end{aligned}
$$


We find $c_{e}^{H}=1.4359, c_{s}^{H}=0.3585, c_{e}^{L}=0.1722$ and $c_{s}^{L}=0.1806$. Thus, overall, the flow costs of posting a vacancy for high-skilled workers equals $c^{H}=1.4359+0.3585+0.1014=1.8958$ and for low-skilled workers it equals $c^{L}=0.1722+0.1806+0.1087=0.4615$.

Remaining Parameters. Ten parameters remain to be determined: the values of non-market activity, $z^{H}, z^{L}$, worker's bargaining weights, $\beta^{H}, \beta^{L}$, the matching function parameters, $\chi^{H}$, $\chi^{L}, \gamma^{H}, \gamma^{L}$, and depreciation factors for capital structures and equipment, $d_{s}^{*}, d_{e}^{*}$. We choose the values for these parameters to match the data on the average value for labor market tightness for skilled and unskilled workers, the elasticity of wages with respect to aggregate productivity, the relative elasticity of wages with respect to aggregate productivity of skilled and unskilled workers, the average values for the job-finding rates of skilled and unskilled workers, the elasticity of the aggregate job-finding rate with respect to aggregate labor market tightness, the relative elasticity of the job-finding rate with respect to aggregate labor market tightness of skilled and unskilled workers, and the standard deviations of capital structures and equipment. Thus, there are ten targets, all described in the previous paragraphs, to pin down ten parameters.

To find the values of these parameters we solve the model numerically according to the computational algorithm described in Appendix II. The performance of the model in matching calibration targets is described in Table 1 . We are able to match the targets almost exactly. Calibrated parameter values can be found in Table 2. To understand these results, it is useful to recall how the two key parameters - the bargaining power and the value of non-market activity - are determined in the homogeneous worker case (Hagedorn and Manovskii, 2008a). The bargaining power is chosen to match the elasticity of wages, since a higher bargaining power of workers makes wages more responsive to changes in productivity. The level of non-market activity is then chosen to match the average level of wages. The average level of wages, holding fixed other parameters such as the separation rate and the interest rate, depends one-for-one on expected hiring costs $c / \phi$, since a higher level of expected costs requires higher profits and thus lower average wages. The same logic applies here. Since expected vacancy posting costs $c / \phi$ are about four times higher for high-skilled workers than for low-skilled workers (relative to productivity), $z^{H}$ is substantially lower than $z^{L}$ (relative to productivity). The bargaining power is again chosen to match the elasticity of wages with one modification. We match 
the elasticity of wages with respect to average productivity and not with respect to marginal productivity, since the latter is not directly observable. For the targeted elasticity it holds that $\epsilon_{w^{T}, p}=\epsilon_{w^{T}, p^{T}} \cdot \epsilon_{p^{T}, p}$, which makes a difference, since $\epsilon_{p^{T}, p}$ does not equal one $\left(\epsilon_{x, y}\right.$ denotes the elasticity of $x$ with respect to $y$.). We find that $\epsilon_{p^{H}, p}=1.316$ and $\epsilon_{p^{L}, p}=0.935$, since changes in capital equipment mainly affect $p^{H}$. In equilibrium, the effect due to a higher volatility of productivity for high-skilled workers outweighs the effect due to a higher productivity elasticity of their wages, implying a lower bargaining power for them compared to low-skilled workers. A similar reasoning applies to measuring the elasticity of the matching function. It is identified by the elasticity of the job-finding rate with respect to the aggregate market tightness $\theta$ because $\theta^{T}$ is not observable. It holds that $\epsilon_{f^{T}, \theta}=\epsilon_{f^{T}, \theta^{T}} \cdot \epsilon_{\theta^{T}, \theta}$. We find that $\epsilon_{\theta^{H}, \theta}=0.837$ and $\epsilon_{\theta^{L}, \theta}=1.056 .^{16,17}$ The choice of the remaining parameters is simple. The matching function efficiency parameter $\chi^{T}$ determines the job finding rate and the depreciation factors are chosen to match the standard deviations of capital structures and equipment.

\section{Business-Cycle Properties of the Model}

The statistics of interest, computed from quarterly U.S. data from 1979:1-2006:4 and the results from the calibrated model are presented in Table 3.

Aggregate Results. A comparison between the corresponding statistics reveals that the model matches the key business-cycle facts quite well. In particular, the volatility of aggregate labor market tightness, unemployment, and vacancies is quite close to that in the data. Moreover, the model generates a strong negative correlation between unemployment and vacancies, i.e., the Beveridge curve.

Results by Skill Group. In the data the unemployment rate is $2.6 \%$ for skilled workers and $8.4 \%$ for unskilled ones. Both of these rates are highly volatile, with respective standard

\footnotetext{
${ }^{16}$ Note that $f^{T}\left(\theta^{T}\right)=\chi^{T}\left(\theta^{T}\right)^{1-\gamma^{T}}$ and $\frac{\left(1-\gamma^{H}\right) \epsilon_{\theta} H, \theta}{\left(1-\gamma^{L}\right) \epsilon_{\theta} L, \theta}=\frac{0.801 \cdot 0.837}{0.471 \cdot 1.056}=1.348$, very close to the target for $\epsilon_{f^{H}, \theta} / \epsilon_{f^{L}, \theta}$. The small difference arises since we compute our targets on model generated data.

${ }^{17}$ An anonymous referee generously pointed out to us that, consistently with our findings, one observes a negative relationship between the unemployment elasticity of the matching function and the employment share of skilled labor in cross-industry data available in Table C14 of the Online Appendix to Sahin, Song, Topa, and Violante (2014).
} 
Table 1: Matching the Calibration Targets.

\begin{tabular}{llll}
\hline & Target & \multicolumn{2}{c}{ Value } \\
\hline & & Data & Model \\
\cline { 4 - 4 } 1. & Elasticity of wages wrt agg. productivity, $\epsilon_{w, p}$ & 0.674 & 0.671 \\
2. & Relative elasticity of wages wrt agg. productivity, $\epsilon_{w^{H}, p} / \epsilon_{w^{L}, p}$ & 1.770 & 1.774 \\
3. & Skilled job-finding rate, $f^{H}$ & 0.106 & 0.105 \\
4. & Unskilled job-finding rate, $f^{L}$ & 0.127 & 0.126 \\
5. & Skilled average market tightness, $\theta^{H}$ & 1.044 & 1.047 \\
6. & Unskilled average market tightness, $\theta^{L}$ & 0.586 & 0.585 \\
7. & Elasticity of agg. job-finding wrt agg. market tightness, $\epsilon_{f, \theta}$ & 0.500 & 0.513 \\
8. & Relative elas. of job-finding wrt agg. mrkt tightness, $\epsilon_{f^{H}, \theta} / \epsilon_{f^{L}, \theta}$ & 1.335 & 1.332 \\
9. & Standard deviation of capital structures & 0.003 & 0.003 \\
10. & Standard deviation of capital equipment & 0.010 & 0.010 \\
\hline
\end{tabular}

Note - The table describes the performance of the model in matching the calibration targets.

Table 2: Calibrated Parameter Values.

\begin{tabular}{lll}
\hline Parameter & Definition & Value \\
\hline$z^{H}$ & skilled value of non-market activity (share of their productivity) & 0.813 \\
$z^{L}$ & unskilled value of non-market activity (share of their productivity) & 0.929 \\
$\beta^{H}$ & skilled workers' bargaining power & 0.069 \\
$\beta^{L}$ & unskilled workers' bargaining power & 0.112 \\
$\gamma^{H}$ & skilled matching function elasticity & 0.199 \\
$\gamma^{L}$ & unskilled matching function elasticity & 0.529 \\
$\chi^{H}$ & skilled matching function efficiency & 0.102 \\
$\chi^{L}$ & unskilled matching function efficiency & 0.164 \\
$d_{s}^{*}$ & depreciation factor of capital structures & 11.200 \\
$d_{e}^{*}$ & depreciation factor of capital equipment & 1.399 \\
\hline
\end{tabular}

Note - The table contains the calibrated parameter values in the benchmark calibration. 
Table 3: Data and Results from the Calibrated Model.

\begin{tabular}{|c|c|c|c|}
\hline & \multirow[t]{2}{*}{ Statistic } & \multicolumn{2}{|c|}{ Value } \\
\hline & & Data & Mode \\
\hline 1. & St. dev. of agg. productivity, $p$ & 0.013 & 0.013 \\
\hline 2 . & Autocorr. of agg. productivity, $p$ & 0.765 & 0.765 \\
\hline 3. & St. dev. of agg. unemployment, $u$ & 0.090 & 0.086 \\
\hline 4 . & St. dev. of agg. vacancies, $v$ & 0.116 & 0.110 \\
\hline 5 . & St. dev. of agg. market tightness, $\theta$ & 0.202 & 0.196 \\
\hline 6 . & Corr. of agg. unemployment and vacancies & -0.910 & -0.777 \\
\hline 1. & St. dev. of skilled productivity, $p^{H}$ & - & 0.018 \\
\hline 2 . & Autocorr. of skilled productivity, $p^{H}$ & - & 0.782 \\
\hline 3. & St. dev. of skilled unemployment, $u^{H}$ & 0.111 & 0.114 \\
\hline 4 . & St. dev. of skilled vacancies, $v^{H}$ & - & 0.078 \\
\hline 5 . & St. dev. of skilled market tightness, $\theta^{H}$ & - & 0.162 \\
\hline 1. & St. dev. of unskilled productivity, $p^{L}$ & - & 0.013 \\
\hline & Autocorr. of unskilled productivity, $p^{L}$ & - & 0.763 \\
\hline & St. dev. of unskilled unemployment, $u^{L}$ & 0.085 & 0.083 \\
\hline & St. dev. of unskilled vacancies, $v^{L}$ & - & 0.133 \\
\hline 5 . & St. dev. of unskilled market tightness, $\theta^{L}$ & - & 0.206 \\
\hline
\end{tabular}

Note - Seasonally adjusted aggregate unemployment, $u$, is constructed by the Bureau of Labor Statistics (BLS) from the Current Population Survey (CPS). Seasonally adjusted skill-group unemployment, $u^{H}$ and $u^{L}$, is constructed by the authors from the monthly Current Population Survey (CPS). The seasonally adjusted help-wanted advertising index, $v$, is constructed by the Conference Board. $u, u^{H}, u^{L}$, and $v$ are quarterly averages of monthly series. Average labor productivity $p$ is seasonally adjusted quarterly real non-farm business output constructed by the BLS from the NIPA divided by non-farm business employment from the monthly Current Population Survey. All variables are reported in logs as deviations from an HP trend with smoothing parameter 1600 . 
deviations of the HP-filtered logged unemployment rate of 0.111 and 0.085 . Thus, while lowskilled workers account for most of the fluctuations in unemployment, the unemployment rate of skilled workers is even more volatile in percentage terms. ${ }^{18}$

The model does an excellent job in matching these observations. It generates unemployment rates of $2.6 \%$ for skilled workers and $8.4 \%$ for unskilled ones, with respective standard deviations of the HP-filtered logged unemployment rate of 0.114 and 0.083 . To understand these results we compute these statistics twice for two economies populated by homogeneous agents only. The first economy is populated by low skilled workers only and we thus use the parameters for unskilled workers from our heterogeneous agent economy. The second economy is populated by high skilled workers only and we thus use the parameters for skilled workers from our heterogeneous agent economy. We find that for the skilled worker economy, market tightness is 9.2 times more volatile than their productivity. This high value, despite a low value of $z^{H}=0.813$, is mainly due to two differences between an economy consisting only of skilled workers and the representative agent economy (the homogeneous agent economy calibrated to the same aggregate statistics as in this paper). First, the productivity process for high-skilled workers is more persistent than for the representative agent. Second, the matching function elasticity for skilled workers, $\gamma^{H}$, equals 0.199 whereas this elasticity equals 0.5 in the representative agent case. Equation (27) in Footnote 19 explains why such a difference in the matching function elasticities results in a different productivity elasticity of market tightness. The high ratio of the volatility of market tightness to the volatility of productivity then translates into a high volatility of market tightness since the productivity process for high-skilled workers is also more volatile than for the representative agent.

For unskilled workers, the standard deviation of HP-filtered $\log$ market tightness $\theta^{L}$ is 0.206, which is 15.8 times higher than the volatility of their productivity. This higher volatility for low-skilled workers is due to a higher value of $z^{L}=0.929$ (relative to their productivity). In the representative agent model of Hagedorn and Manovskii (2008a), a value of $z=0.94$ would be required to generate a volatility of market tightness of 0.206 . A value of $z=0.929$ would generate a volatility of only 0.177 in that model. The difference is due to a separation rate of low-skilled workers that is higher than the one used in the representative agent economy in

\footnotetext{
${ }^{18}$ Interestingly, Castro and Coen-Pirani (2008) show that over the time period that we study even employment of skilled workers is more volatile than that of low-skilled workers.
} 
Hagedorn and Manovskii (2008a). ${ }^{19}$

The matching function translates the volatility of market tightness into volatile unemployment. For each group, the steady state elasticity of unemployment with respect to productivity can be expressed as

$$
\epsilon_{u^{T}, p^{T}}=\epsilon_{u^{T}, f^{T}} \cdot \epsilon_{f^{T}, \theta^{T}} \cdot \epsilon_{\theta^{T}, p^{T}}=-\left(1-\frac{u^{T}}{N^{T}}\right)\left(1-\gamma^{T}\right) \epsilon_{\theta^{T}, p^{T}}
$$

Our finding that $1-\gamma^{H}=1-0.199$ is substantially larger than $1-\gamma^{L}=1-0.529$ explains why high-skilled unemployment is more volatile than low-skilled unemployment, although the opposite ordering between groups holds for market tightness.

The aggregate statistics targeted in this paper differ from those in Hagedorn and Manovskii (2008a). We now calibrate the linear model with homogeneous workers in Hagedorn and Manovskii (2008a) to match these same aggregate statistics. In particular, we target a wage elasticity of 0.67 (instead of 0.45 in Hagedorn and Manovskii (2008a)) and also make the distinction between the total separation rate and the separation rate into unemployment. We find a standard deviation of market tightness of 0.11 and a standard deviation of unemployment of 0.049 , which represent only about one-half of the corresponding numbers in the data. As we have shown above, only after we allow for heterogeneity, the model is able to replicate the observed volatilities. Two simple observations explain this finding. First, the volatility of unemployment is an increasing and convex function of $z$ (see equation (27)). Second, the calibrated value of $z$ in the homogeneous worker model lies between the two values $z^{H}$ and $z^{L}$ and is close to their weighted average. As a consequence, low-skilled unemployment and thus also overall unemployment are substantially more volatile than unemployment in the homogeneous worker model. To summarize, we find that the extended MP model calibrated using the strategy proposed in Hagedorn and Manovskii (2008a) is consistent with labor market volatilities in the aggregate, once we allow for heterogeneity, and in subgroups.

19 Hagedorn and Manovskii (2008a) derive, in the model without aggregate uncertainty, the elasticity of labor market tightness with respect to aggregate productivity to be:

$$
\epsilon_{\theta, p}=\frac{p}{p-z} \frac{\beta f(\theta)+(1-\delta(1-s)) / \delta}{\beta f(\theta)+(1-\eta)(1-\delta(1-s)) / \delta},
$$

where $\eta$ is the elasticity of $f(\theta)$ with respect to $\theta$. This equation may be used to quite accurately evaluate the impact of various parameter values, such as the separation rate, on the volatility of market tightness. 
Robustness. The only target in our benchmark calibration that is not standard is the elasticity of wages with respect to aggregate productivity. Recall that we define productivity as non-farm business output divided by employment from the monthly Current Population Survey. Shimer (2005a) used the same measure of output but divided it by employment measured in the Current Employment Statistics. The estimated elasticity of wages with respect to aggregate productivity is affected by this choice. Our measure of productivity implies an elasticity of 0.67 , while Shimer's measure implies an elasticity of only $0.5 .^{20}$ We now recalibrate the model to match the same calibration targets but target a low wage elasticity of 0.5 .

The performance of the model in matching the calibration targets with a low wage elasticity, the calibrated parameter values, and the results are described in Appendix Tables A-1, A-2, and A-3, respectively. The changes in the calibrated values of the bargaining power $\beta$ and the value of non-market activity $z$ are as expected. A lower value for the targeted wage elasticity for both groups leads to lower values for the bargaining power of both types, $\beta^{H}$ and $\beta^{L}$. Since the expected costs of posting vacancies remain unchanged, per period profits and thus average wages do not change either. To generate the same level of wages with a lower bargaining power requires then a higher value of non-market activity for both types, $z^{H}$ and $z^{L}$. Higher values of non-market activity result in more volatile labor market variables in the aggregate and for each worker type as compared to the benchmark calibration.

An additional benefit of this experiment is that it (coincidentally) targets virtually the same aggregate statistics computed over the 1951-2004 period as in Shimer (2005a) and Hagedorn and Manovskii (2008a). For comparison, we reproduce these statistics in Column (1) of Appendix Table A-3 and the results from the calibration of the linear MP model with homogeneous workers in Column (3) (targeting the same aggregate statistics as in the model with heterogeneity). A comparison of the results based on the model with worker heterogeneity with the results from the linear model implies that the model with worker heterogeneity again generates a higher volatility of aggregate labor market statistics and is closer to the data than the homogeneous worker model.

A new feature of our calibration is that we make a distinction between the total separation rate and the separation rate into unemployment. We now recalibrate the model to match the

\footnotetext{
${ }^{20}$ The differences between the cyclical properties of these series are documented in Hagedorn and Manovskii (2011), who also argue why a productivity measure based on CPS employment might be preferred.
} 
same calibration targets but without making this distinction. The performance of the model in matching the calibration targets, calibrated parameter values, and results are described in Appendix Tables A-4, A-5, and A-6, respectively. A lower total separation rate increases expected profits from a filled vacancy. Since vacancy posting costs are unchanged, a higher value of non-market activity $z$ is required to keep profits unchanged. A higher value of $z$ leads to more volatility in market tightness and in wages. Thus a lower value of the bargaining weight is chosen to match a wage elasticity of 0.67. Again the model with heterogeneity is closer to the data, since the linear model with homogeneous workers generates too little volatility.

Finally, we have assumed throughout the paper that the two shocks, $\epsilon_{A, t}$ and $\epsilon_{q, t}$ are independent. Estimating their correlation in the data, we obtain a correlation of 0.2644 . We have recalibrated the model with this correlation and found that our results are not affected. Introducing this correlation makes capital slightly more volatile because the price of capital equipment is lower when TFP is higher. However, the depreciation factors adjust to match capital volatility in the data, and all other statistics remain unchanged.

\section{Tax Policy Experiments}

In this section we investigate the effects of changes in tax policies under two scenarios. First, when productivity is exogenous and second, when productivity is endogenous because workers are heterogeneous and interact through the production side of the economy. Specifically, we consider how unemployment responds to changes in the labor income tax rate, in the sales tax and in the capital income tax rate in the two scenarios. The effects of these policy changes are easy to compute since they are equivalent to changing the value of non-market activity, or equivalently changing labor productivity. Hagedorn and Manovskii (2008a) show that the equilibrium with a labor $\operatorname{tax}$ rate $\tau_{w}$ is equivalent to the equilibrium without a labor tax but where $z$ is replaced by $\frac{z}{1-\tau_{w}}$. An equilibrium with a sales tax of $\tau_{s}$ is equivalent to an equilibrium without a sales tax but where productivity $p$ is replace by $p\left(1-\tau_{s}\right)$. Finally, imposing a capital income tax rate $\tau_{k}$ changes optimal capital accumulation in a steady state 
(with the normalization $q=1$ ) according to the two equations:

$$
\begin{aligned}
& \left(F_{k_{s}}(t+1)-d_{s}\right)\left(1-\tau_{k}\right)=\frac{1}{\delta}-1 \\
& \left(F_{k_{e}}(t+1)-d_{e}\right)\left(1-\tau_{k}\right)=\frac{1}{\delta}-1 .
\end{aligned}
$$

The direct impact of taxing capital income is to lower investment, which then leads to a drop in labor productivity.

In the next section, we analyze how productivity and unemployment respond to tax policy changes theoretically before assessing this relationship quantitatively. We study the effects of changes in $z$ (corresponding to a change in labor taxes), but all of our results fully apply to changes in consumption taxes and capital income tax rates since only the difference between $p$ and $z, p-z$ matters.

\subsection{Theoretical Analysis}

In this section, we show that a change in $z$ changes not only employment but also productivity, which can mitigate or amplify the changes in employment. If, for example, an increase in $z$ increases productivity, the drop in employment is smaller than it would be with a constant level of productivity. To show this we consider a simplified (relative to equation (2)) constant return to scale (CRS) production technology

$$
y_{t}=G(l, h, k)
$$

where $k$ is capital and $l$ and $h$ are two different labor types, and $G$ is increasing and concave in each argument. ${ }^{21}$

A drop in $l$ (due to an increase in $z^{l}$ ) increases the productivity $G_{l}$ of low-skilled workers if the levels of $h$ and $k$ are unchanged. But $h$ and $k$ adjust as well, and this adjustment can overturn this conclusion, depending on the properties of $G$. The following sections investigate these properties.

\footnotetext{
${ }^{21}$ The technology in (2) takes this form for $\alpha=0$. Since (2) combines capital structures and $G$ through a Cobb-Douglas aggregator, assuming (2) would not change the conclusions of this section. The Cobb-Douglas specification implies that capital structures change one-for-one with $G$.
} 


\subsubsection{Equilibrium Conditions for Capital, Employment and Market Tightness}

Given the production function $G$, we now consider how the productivities $G_{l}, G_{h}$ and $G_{k}$, labor inputs $l$ and $h$, capital $k$ and the policy parameter $z$ are related.

Capital solves the first-order condition ( $d$ is the depreciation rate)

$$
G_{k}=\frac{1}{\delta}-(1-d)
$$

which defines capital implicitly as a function of $l$ and $h: k(l, h)$.

For the two labor inputs, we can derive in the case of no aggregate uncertainty (see Hagedorn and Manovskii, 2008a) the following relationship between market tightness and productivity for each group (we suppress the dependence on type $T$ ).

$$
\frac{1-\delta(1-s)}{\delta q(\theta)}+\beta \theta=\frac{p-z}{c}(1-\beta)
$$

The steady state conditions for employment $l$ and $h$ are

$$
l=\frac{f^{L}\left(\theta^{L}\right)}{s^{L}+f^{L}\left(\theta^{L}\right)} \quad \text { and } \quad h=\frac{f^{H}\left(\theta^{H}\right)}{s^{H}+f^{H}\left(\theta^{H}\right)} .
$$

The last two equations together imply two functions that relate the level of employment to $p$ and $z$ :

$$
\begin{gathered}
l=L\left(p^{l}, z^{l}\right), \\
h=H\left(p^{h}, z^{h}\right) .
\end{gathered}
$$

Denote the marginal productivity of group $l$ :

$$
p^{l}=G_{l}(l, h, k)
$$

and the marginal productivity of group $h$ :

$$
p^{h}=G_{h}(l, h, k)
$$

Taking into account that capital $k$ is a function of $l$ and $h, k(l, h)$, allows us to express productivities as functions of $l$ and $h$ only

$$
\begin{gathered}
p^{l}=G_{l}(l, h, k(l, h))=\pi^{l}(l, h), \\
p^{h}=G_{h}(l, h, k(l, h))=\pi^{h}(l, h) .
\end{gathered}
$$


Plugging the expression for $L\left(p^{l}, z^{l}\right)$ and $H\left(p^{h}, z^{h}\right)$ into the functions $\pi$, results in two functions $A$ and $B$ :

$$
\begin{aligned}
p^{l} & =A\left(p^{l}, z^{l}, p^{h}, z^{h}\right)=\pi^{l}\left(L\left(p^{l}, z^{l}\right), H\left(p^{h}, z^{h}\right)\right), \\
p^{h} & =B\left(p^{l}, z^{l}, p^{h}, z^{h}\right)=\pi^{h}\left(L\left(p^{l}, z^{l}\right), H\left(p^{h}, z^{h}\right)\right),
\end{aligned}
$$

which jointly describe the two productivity levels $\left(p^{l}, p^{h}\right)$ as a fixed point, depending on the two parameters $\left(z^{l}, z^{h}\right)$. We now want to investigate how changing $\left(z^{l}, z^{h}\right)$ affects the fixed point $\left(p^{l}, p^{h}\right)$.

In Appendix III we establish the following results $\left(\epsilon_{x, y}\right.$ denotes the elasticity of $x$ w.r.t $\left.y\right)$ :

- If $\left(\epsilon_{L, z^{l}}-\epsilon_{H, z^{h}}\right)>0$ then productivity increases for low-skilled workers and decreases for high-skilled workers in response to a one percent increase in both $z^{l}$ and $z^{h}$.

- Low skilled labor increases and high skilled labor decreases due to the change in productivity. If in addition $\epsilon_{L, p^{l}}-\frac{p^{l}}{p^{h}} \epsilon_{H, p^{h}}>0$ then overall employment increases.

The assumption for the first result states that employment of low skilled workers responds stronger than employment of high skilled workers to a change in $z$. This implies that the capital stock does not drop enough to keep the productivity of low-skilled workers invariant and thus their productivity increases. The capital stock drops too much to keep the productivity of high-skilled workers invariant and thus their productivity decreases. If, however, $\epsilon_{L, z^{l}}-$ $\epsilon_{H, z^{h}}=0$ then productivity remains unchanged as the capital stock can adjust to keep both productivities invariant. The second result then states that these productivity changes result in the obvious employment changes for the two groups. If productivity increases employment increases and if productivity decreases employment decreases. The last assumption ensures that the employment increase for low skilled workers is larger than the employment decrease for high skilled workers.

\subsection{Quantitative Evaluation}

In this section we investigate quantitatively the effect of labor, sales and capital income tax rates on unemployment and productivity. In each experiment we keep all the parameter values the same as in our benchmark calibration except for increasing the value of non-market activity 
$z$ in the case of a labor tax or decreasing labor productivity $p$ in case of a sales or capital income tax. An increase in the labor income tax rate by one percentage point amounts to increasing $\left(z^{L}, z^{H}\right)$ to $\left(\frac{z^{H}}{1-0.01}, \frac{z^{L}}{1-0.01}\right)$. A one percentage point increase in the sales tax rate leads to a decrease of labor productivity from $\left(p^{L}, p^{H}\right)$ to $\left((1-0.01) p^{L},(1-0.01) p^{H}\right)$. Finally a one percentage point increase in the capital income tax rate lowers the return on capital $r$ to $(1-0.01) r$, as described above.

In all these experiments we assume that the value of non-market activity is invariant with respect to tax policy. ${ }^{22}$ This is obviously a strong assumption. For example, unemployed workers also have to pay a sales tax and thus suffer from a tax increase to the extent that $z$ measures not only the value of leisure but also receiving unemployment benefits or being self-employed. For example, if a third of the value of $z$ reflects unemployment insurance, then the value of $z$ should be decreased by a third of a percentage point dampening the policy effects by about a third. A similar argument applies to a labor income tax rate if unemployment benefits are taxed as in, e.g., the U.S., or are determined as a fraction of aftertax wages, as in, e.g., Germany. If the latter case, an increase in labor tax rates lowers the net wage and thus unemployment benefits for a fixed replacement ratio. Finally, we did not model a direct link between the level of productivity and $z$. It is likely, however, that such a relationship exists. Hall and Milgrom (2008) introduce curvature into preferences in the MP model. With some assumption on preference parameters (they assume preferences inconsistent with balanced growth) they derive $z$ as a function of consumption levels of employed and unemployed workers (which would be affected by, e.g., permanent changes in productivity). The RBC model with balanced growth preferences may provide some guidance to the direction and magnitude of the impact of a change in $p$ on $z$. For example, a change in capital income tax rate in that model has no effect on employment (Prescott, 2004). This would correspond to $z$ decreasing by the same amount as $p$ in response to an increase in $\tau_{k}$. Therefore the numbers found here should be considered upper bounds on policy effects (see Appendix IV for an additional illustration) ${ }^{23}$ However, this reasoning does not affect our comparison of policy

\footnotetext{
${ }^{22}$ Note, that as we mentioned above the increase in labor tax is equivalent to an increase in $z$. This does not contradict the invariance assumption because there are no additional effects of the tax change on $z$.

${ }^{23}$ Pissarides (1998) also finds that the magnitude of unemployment changes depend on whether unemployment benefits are indexed to wages (or not), with much larger effects if unemployment benefits $(z)$ are invariant.
} 
effects in models with endogenous and exogenous productivity since we compute percentage differences.

The results of performing these experiments are presented in Column 1 of Table 4. For labor income tax rates we find that the overall unemployment rate increases by $6.7 \%$ (from $7.0 \%$ to $7.5 \%$ ), the low skill unemployment rate increases by $6.6 \%$ (from $8.6 \%$ to $9.2 \%$ ), and the high skill unemployment rate increases by $7.5 \%$ (from $2.7 \%$ to $2.9 \%$ ). For the sales tax the findings are very similar (as they would also be in an RBC model with Walrasian labor markets). The overall unemployment rate increases by $7.3 \%$, the low skill unemployment rate increases by $7.1 \%$, and the high skill unemployment rate increases by $9.1 \%$. Finally, for the capital income tax we find that the overall unemployment rate increases by $0.9 \%$, the low skill unemployment rate increases by $0.8 \%$, and the high skill unemployment rate increases by $1.9 \%$.

Section 5.1 implies that the change in unemployment can be decomposed into the effect due to productivity changes and a composition effect. Column 2 of Table 4 illustrates that with a constant level of productivity, the response of low-skilled unemployment to the same increase in labor tax rates would be to increase by $8.5 \%$ and high-skilled unemployment would increase by $7.2 \%$ leading to the overall increase in unemployment with unchanged productivity of $8.4 \%$. The endogenous change in productivity reduces the strength of these effects. As reported in Table 5, productivity of low-skilled workers increases by $0.194 \%$ and productivity of high skilled decreases by $0.028 \%$. This accounts for the smaller increases in unemployment in the model with endogenous productivity, with the extent of the difference reported in Column 3 of Table 4. Tables 4 and 5 show that the effects of changes in sales taxes are very similar to the effects of changing the labor tax. In both cases the endogenous change in productivity dampens the effects of changes in tax rates by about $25 \%$. The effects of changes in capital income tax rates are dampened even stronger, by about 38\%. Since capital income taxes affects labor productivity only indirectly, the unemployment rate responds by less than in the case of labor or sale taxes.

These policy effects are considerably lower than those implied by the standard MP model with homogeneous workers. A meaningful comparison of the size of policy effects between the two models requires that they both generate the same amount of volatility in market tightness. Otherwise, one model could generate small policy effects just because it does not 
Table 4: Semi-Elasticities of Unemployment with Respect to Changes in Tax Rates.

\begin{tabular}{lccc}
\hline & $\begin{array}{c}\text { Endogenous Prod. } \\
(1)\end{array}$ & $\begin{array}{c}\text { Exogenous Prod. } \\
(2)\end{array}$ & $\begin{array}{c}\text { Difference } \\
(3)\end{array}$ \\
\hline & \multicolumn{3}{c}{ Labor Income Tax } \\
Overall Unemployment & 6.705 & 8.409 & 25.416 \\
Low Skilled Unemployment & 6.611 & 8.547 & 29.291 \\
High Skilled Unemployment & 7.504 & 7.238 & -3.545 \\
& & & \\
& & Sales Tax & \\
Overall Unemployment & 7.343 & 9.161 & 24.749 \\
Low Skilled Unemployment & 7.139 & 9.186 & 28.668 \\
High Skilled Unemployment & 9.077 & 8.951 & -1.389 \\
& & & \\
& & Capital Income Tax & \\
Overall Unemployment & 0.907 & 1.249 & 37.689 \\
Low Skilled Unemployment & 0.793 & 1.274 & 60.830 \\
High Skilled Unemployment & 1.887 & 1.032 & -45.312 \\
\hline
\end{tabular}

Note - Entries are semi-elasticities with exogenous and endogenous productivity: percentage changes of overall unemployment, high skilled unemployment and low skilled unemployment in response to a one percentage point increase in the labor income tax rate, the sales tax rate and the capital income tax rate, respectively. The column "Difference" reports the percentage difference between Columns 1 and 2 .

generate much volatility (an arbitrarily low value of $z$ would ensure this). To generate a volatility of 0.296 in the linear model requires that $z=0.928$ (all other parameters except for vacancy posting costs are chosen to match the same aggregate statistics as in our benchmark calibration). For this value of $z$ we find a semi-elasticity of the overall unemployment rate of $9.5 \%$ for sales taxation, $8.6 \%$ for labor taxation and $1.2 \%$ for capital taxation.

The results are even stronger if one considers the low wage elasticity calibration. In that case we have to set $z=0.942$ in the standard model to generate a volatility of 0.246 , the volatility generated by our model with heterogeneous agents (and a low wage elasticity) as described in Appendix Table A-6. This implies a semi-elasticity of $13.3 \%$ for sales taxation, 
Table 5: Percentage Change of Productivity in Response to Changes in Tax Rates.

\begin{tabular}{lcc}
\hline & $\begin{array}{c}\text { Endogenous Prod. } \\
(1)\end{array}$ & $\begin{array}{c}\text { Exogenous Prod. } \\
\text { Labor Income Tax }\end{array}$ \\
\hline Overall Productivity & 0.179 & 0.014 \\
Low Skilled Productivity & 0.194 & 0.000 \\
High Skilled Productivity & -0.028 & 0.000 \\
& & \\
& & Sales Tax \\
Overall Productivity & 0.191 & 0.010 \\
Low Skilled Productivity & 0.204 & 0.000 \\
High Skilled Productivity & -0.013 & 0.000 \\
& \multicolumn{2}{c}{ Capital Income Tax } \\
Overall Productivity & -0.127 & 0.000 \\
Low Skilled Productivity & 0.096 & 0.000 \\
High Skilled Productivity & -0.226 & 0.000 \\
\hline
\end{tabular}

Note - percentage changes of overall productivity (output per worker), high skilled productivity and low skilled productivity (both marginal productivities) in response to a one percentage point increase in the labor income tax rate, the sales tax rate and the capital income tax rate, respectively. Productivity is before subtracting sales taxes.

a semi-elasticity of $12.6 \%$ for labor taxation and a semi-elasticity of 2.0 for capital taxation, whereas our model with heterogeneity implies semi-elasticities of $9.3 \%, 8.7 \%$ and $1.2 \%$, respectively.

\subsection{Empirical Evidence on the Effects of Policy Changes}

In the previous sections we have established several results on the effects of changes in labor taxation, sales taxation and capital income taxation on unemployment and productivity. We found that the semi-elasticities of unemployment with respect to labor and sales taxes are of about equal size, $7 \%$, whereas capital income taxes have only very small effects. We also 
showed that an increase in both labor and sales taxes leads to a decrease in the skill premium since the productivity of low skilled workers increases whereas the productivity of high skill workers decreases. Furthermore, because of these endogenous productivity responses, the percentage change in the unemployment rate is higher for high skilled than for low skilled workers. Due to this neutralizing effect, we do not expect to find that increases in unemployment are concentrated among low skilled workers. In this section we use cross-country evidence to verify whether these model predictions are consistent with the data. In particular, we ask how much of the differences in unemployment rates between countries can be accounted for by differences in tax policy. Table 6 uses data on tax rates and unemployment rates for the OECD countries to provide some evidence on the empirical effects of taxation. ${ }^{24}$ We regress the $\log$ of the unemployment rate on various tax measures. Thus, the numbers in the table represent the semi-elasticity of unemployment with respect to the respective tax variable. Column (1) establishes that, as expected, capital income taxes have virtually no effect on unemployment whereas the effects of labor and sales taxes are substantial and of similar magnitude. We can thus define a tax wedge as the sum of the labor tax rate and the sales tax rate and we do not expect the results to change. Column (2), which shows the result from a regression of unemployment on this tax wedge and capital income taxation, confirms this. A one percentage point increase in the tax wedge increases unemployment by 8.436 percent. Summing labor and sales taxation seems also appropriate from a fiscal perspective since different governments may choose different combinations of sales and labor taxation to generate the same tax revenue. It is then conceivable that by pure chance high unemployment countries choose, say, labor taxation and low unemployment countries choose sales taxation. A similar argument could apply to capital income taxation and unemployment insurance although the revenue from capital income taxes is much lower than that raised from labor taxes and the expenditures on unemployment insurance are only a small fraction of government expenditures. However,

\footnotetext{
${ }^{24}$ We use data on effective labor, capital, and sales taxes for a number of the OECD countries over 1965-1996 period provided by Enrique Mendoza on his webpage http://econ-server.umd.edu/ mendoza/pp/taxdata.pdf and .../newtaxdata.pdf. The data were constructed using the method described in Mendoza, Razin, and Tesar (1994). Data on the unemployment rates for these countries was provided by Jim Costain on his webpage http://www.econ.upf.edu/ costain/rbcmatch/webpage/bcui.html. See Costain and Reiter (2008) for the detailed description of the data. Since unemployment data used in Costain and Reiter (2008) refers to five-year averages, we average the tax data similarly in the years when it is available.
} 
Table 6: Evidence on the Effects of Taxes on Unemployment

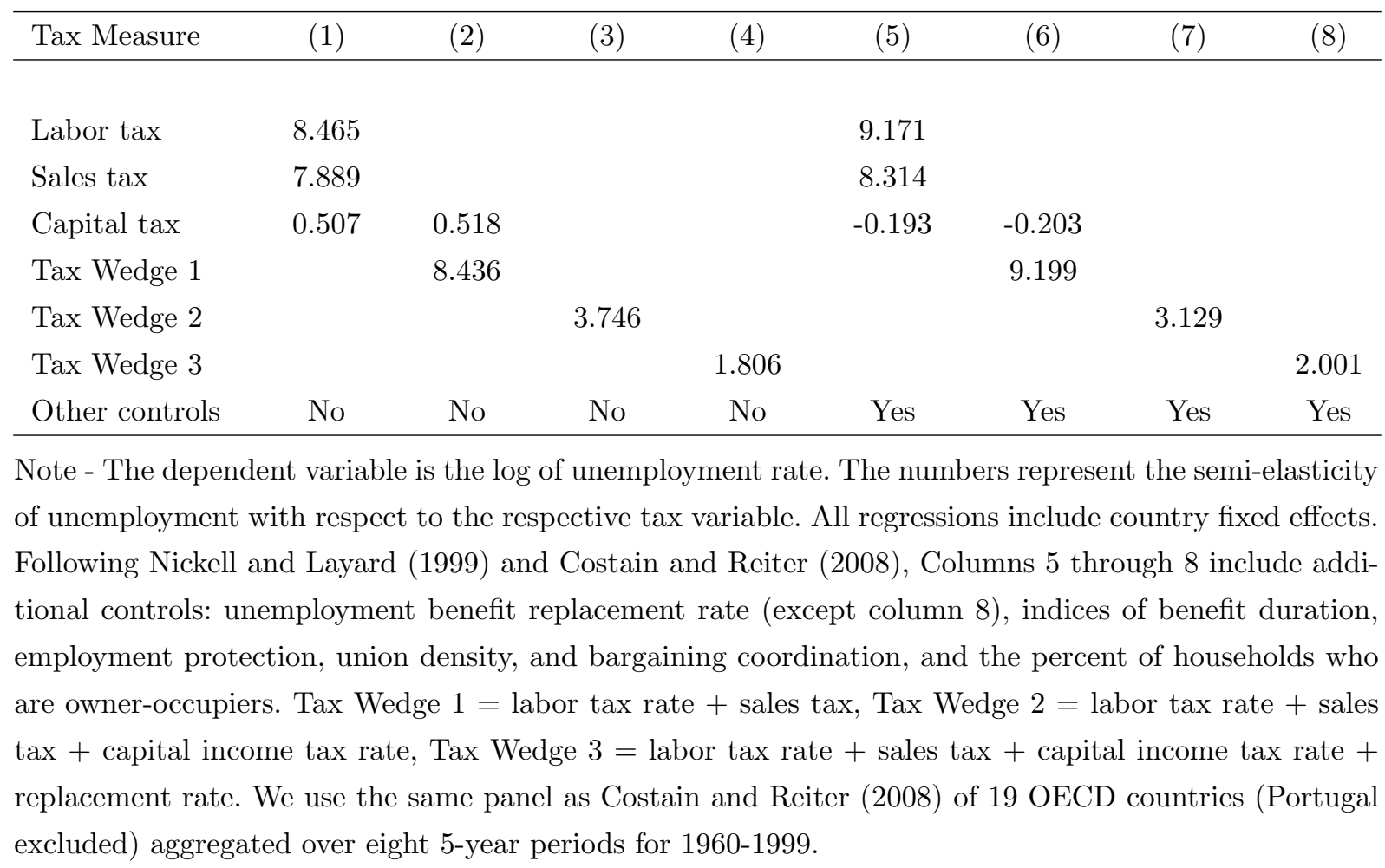

summing all these policy rates seems problematic since they have substantially different effects on unemployment. Columns (3) and (4) show that indeed the effects of these wedges are diluted. ${ }^{25}$ Finally, Columns (5) - (8) redo the experiments from Columns (1) - (4) but add the additional controls used by Costain and Reiter (2008) and Nickell and Layard (1999) that may also affect unemployment. These controls include unemployment insurance replacement rates (not included in column 8 because the replacement rate is already part of Tax Wedge 3), indices of benefit duration, employment protection, union density, and bargaining coordination, and the percent of households who are owner-occupiers. Adding these controls does not significantly affect our results. We therefore conclude that a one percentage point increase in labor or consumption tax rates increases unemployment by about 8 percent. ${ }^{26}$

\footnotetext{
${ }^{25}$ The tax wedge in Costain and Reiter (2008), building on Nickell and Layard (1999), includes income taxes which also fall on capital income.

${ }^{26} \mathrm{An}$ increase in the unemployment rate by 8 percent from $5.7 \%$ (sample mean) to $6.16 \%$ corresponds to a decrease of $100 *$ employment by 0.456 (population has measure one). Gordon (2007) finds similar numbers in his survey of the literature. He reports -0.47 for the response of hours per capita to tax changes and about -0.4 for the response of employment per capita.
} 


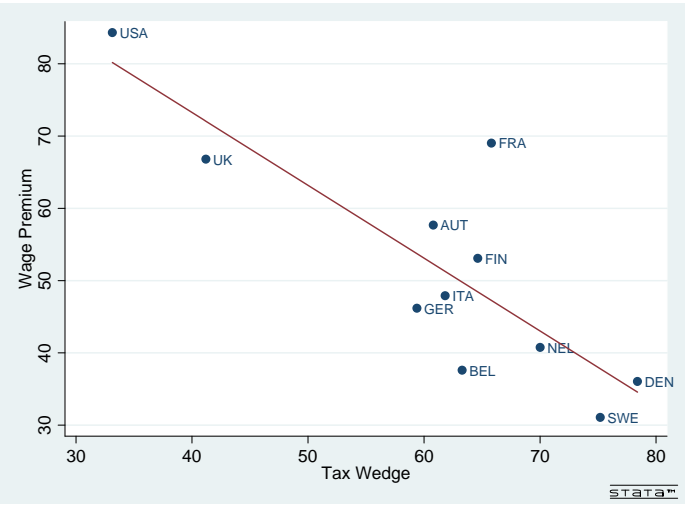

(a) Skill Premium (Men) and Tax Wedge

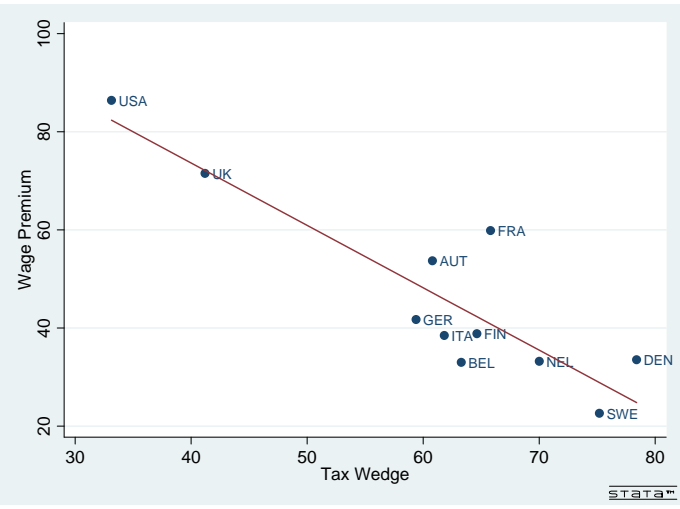

(b) Skill premium (Women) and Tax Wedge

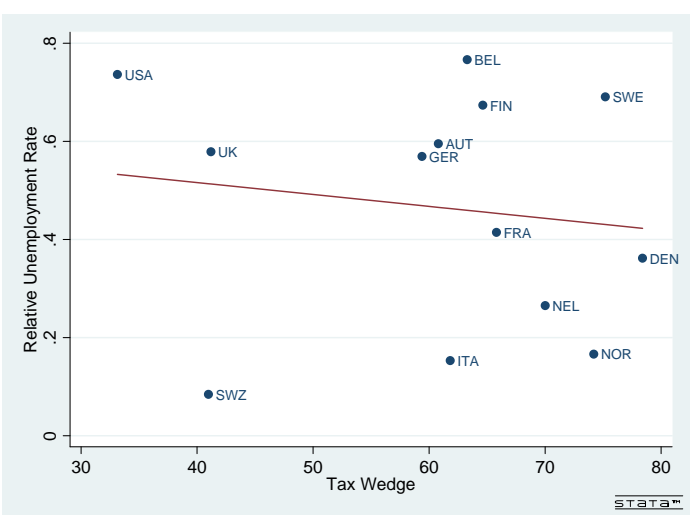

(c) Relative Unemployment and Tax Wedge

Figure 1: Panel a)+b): Tax wedge (sum of labor and sales taxes) in percentage points, Skill premium is the percentage difference in wages between high and low skilled workers. Panel c): relative unemployment rate is $\log$ (low skill unemployment rate over high skill unemployment rate).

We now provide evidence for how the differences in tax policies across countries affect the skill premium and the relative unemployment rates for different skill groups. We use data from a number of the OECD countries from 1996-2000 on the skill premium for both men and women and for the unemployment rates for college and high school workers. ${ }^{27}$ We compute the average of these premia and unemployment rates for each country and we also average the tax

\footnotetext{
${ }^{27}$ The data on skill premium come from Strauss and de la Maisonneive (2007). They use households surveys of the OECD countries in the 1990s to measure the college premium constructed using comparable definitions of wages and schooling groups across countries. Data on unemployment rates by level of education come from Eurostat Table "Unemployment rates of the population aged 25-64 by level of education." Because we have to use different data sources for constructing the variable, they do not always overlap in their coverage. We have data on skill premia, unemployment rates by skill and tax wedges for Austria, Belgium, Denmark, Finland, France, Germany, Italy, Netherlands, Sweden, United Kingdom and United States. For Norway and Switzerland we have only data on tax wedges and unemployment.
} 
wedge (sum of labor and sales taxes) for these countries between 1990-1999. ${ }^{28}$ Figure 1 confirms the predictions of our theory. We find a significant negative effect of the tax wedge on the skill premium for both men (significant slope -1.007) and women (significant slope -1.271) and virtually no effect on the ratio of low skill to high skill unemployment (insignificant slope -0.002), echoing the view expressed in Nickell and Bell (1996) and Gottschalk and Smeeding $(1997) \cdot{ }^{29}$

\section{Conclusion}

We extended the basic Mortensen-Pissarides search and matching model along two dimensions. First, we allowed for ex-ante heterogeneity between workers, low and high skilled. Second, we allowed two technology shocks, neutral and investment-specific, to be the driving forces of the economy. Specifically, we integrated the framework of Krusell, Ohanian, Ríos-Rull, and Violante (2000) - a production function with capital-skill complementarity and two skill-groups - into a business-cycle search and matching model. We calibrated the model using the approach in Hagedorn and Manovskii (2008a) and found that the model accounts well for the cyclical behavior of labor market variables in the aggregate and for each demographic group.

Our calibration implies that the flow value of non-market activity of high-skilled workers is considerably lower than the corresponding value for a representative worker in the model with homogeneous workers. For low-skilled workers the flow value of non-market activity is slightly higher than the value for a representative worker. Nevertheless, in the model, as in the data, the unemployment rates for these two groups of workers are highly and roughly equally volatile over the business cycle. The fact that the unemployment rate of low-skilled workers is highly volatile is not surprising given the results in Hagedorn and Manovskii (2008a). The accounting profits that firms make on these workers are small and thus respond strongly in percentage terms to fluctuations in the marginal product of these workers. The fact that the unemployment rate of highly skilled workers is also highly volatile, despite the fact that the

\footnotetext{
${ }^{28}$ We average the tax wedge over a longer time period to maximize the number of countries in our sample. Restricting ourselves to the period 1995-1999 would shrink our sample to G-7 countries only. Our finding are insensitive to this choice, however.

${ }^{29}$ The short time period and thus very few data prevent a more elaborate empirical investigation such as including more controls or country fixed effects.
} 
accounting profits firms make on them are relatively large, is due to the higher volatility and the higher persistence of their marginal product relative to the representative worker case.

We find that the response of unemployment to changes in taxes is substantially lower in the model with worker heterogeneity than in the model with homogeneous workers if both models generate the same volatility of market tightness. We show that this difference in policy effects is due to an endogenous response of productivity. Consider, for example, an increase in labor taxes. Because the flow utility of unemployment for high-skilled workers is relatively low, a change in taxes does not substantially affect the decisions of firms to post vacancies in a hope of hiring these workers. Thus, they serve as a fixed factor in the aggregate production. Because capital equipment is complementary with these workers and since the stock of highskilled workers is little changed, the stock of capital equipment is little changed as well, even in the long run. In turn, if the productivity of low-skilled workers remained unchanged, a change in policy that squeezes the profits that firms make on them would induce firms to post fewer vacancies and the employment of low-skilled workers would fall. However, as their employment falls, their productivity increases because capital equipment and high-skilled workers remain in place. This increase in productivity of low-skilled workers acts to restore the profits that firms make on these workers and counteracts the effect of the change in the policy. Thus, the endogenous response of productivity significantly dampens the effect of a change in taxes on unemployment. Note that these effects are driven by the presence of worker heterogeneity and not by the curvature in the production per se. With a one-sector Cobb-Douglas production function, capital would adjust after a change in policy to keep the capital-labor ratio and thus productivity constant.

We have shown that the semielasticity of unemployment with respect to changes in the tax wedge implied by the model is quantitatively consistent with the data. Moreover, the model matches the evidence that countries with higher tax rates have higher aggregate productivity, lower skill premia, and higher unemployment rates among both high- and low-skilled workers. This evidence provides support for the key mechanism in the model based on worker heterogeneity.

While our focus in this paper was on understanding the effects of taxation, empirical evidence shows that other policies, such as changes in the generosity of unemployment insurance, also have large effects on unemployment (Hagedorn, Karahan, Manovskii, and Mitman, 2013; 
Hagedorn, Manovskii, and Mitman, 2015). Ljungqvist and Sargent $(1998,2008)$ argue that the rise in European unemployment can be accounted for by the increase in the depreciation rate of human capital upon job displacement interacted with more generous unemployment insurance in Europe. They do not consider the ability of their model to match business cycle facts. We think it would be fruitful to take into account the endogenous response of productivity to policy changes in their framework as well.

While we study the effects of worker heterogeneity in the MP model, a number of papers have recently investigated the quantitative implications of heterogeneity of productivities across jobs (e.g., Hornstein, Krusell, and Violante (2007), Michelacci and Lopez-Salido (2007), Pissarides and Vallanti (2007)). Most closely related to our analysis is the contribution by Hornstein, Krusell, and Violante (2007) who study the effects of labor market policies, including tax wedges, in determining the effect of the faster capital embodied capital change on unemployment. They focus on steady states and do not investigate the response of unemployment to cyclical fluctuations in productivity. Their analysis abstracts from the endogenous response of productivity to changes in tax policies and thus likely features similar elasticities of unemployment with respect to cyclical fluctuations in productivity and taxes. Introducing worker heterogeneity along the lines of our paper into their model would likely help match the differences in these responses in the data. This appears an interesting extension to pursue.

Our analysis in this paper can be described as a comparison of two stationary economies (featuring aggregate shocks to productivity and price of capital equipment that do not have a trend) characterized by different tax rates. Thus, we have abstracted from secular changes in productivity and in the price of capital equipment. Relatedly, we did not study the secular increase in the college premium observed in the U.S. in the 1980s and 1990s. A number of papers, including Acemoglu (1999), Albrecht and Vroman (2002), Shi (2002), Wong (2003), among others, have explored this issue in the MP model that includes worker heterogeneity but the productivity changes are exogenous. Krusell, Ohanian, Ríos-Rull, and Violante (2000) study the effect of a decline in the price of capital equipment on the college premium in a frictionless model. It seems to be an interesting extension to evaluate the effects of a decline in the price of capital equipment in our model and to compare the response of wage inequality, in particular, across countries with different levels of the tax wedge.

Finally, while our focus in this paper is on unemployment, Prescott (2004), Rogerson 
(2008), Rogerson and Wallenius (2009), among others, have studied the effects of tax policies on total hours worked using versions of the real business cycle model. The RBC model features the same trade-off as the basic MP model. As is shown in Prescott (2004), the standard RBC model with labor supply elasticity equal to 3 matches the cross-country differences in hours worked in response to differences in taxes. However, as pointed out in Hansen (1985), with this labor supply elasticity the RBC model generates only about one half of the observed volatility of hours worked over the business cycle. A higher labor supply elasticity is required to match the cyclical movements in hours. However, a higher elasticity would imply counterfactually strong policy effects. Incorporating worker heterogeneity into the RBC model along the lines proposed in this paper will help break the close linkage between the response of hours to changes in productivity and the response to changes in tax rates. Just as the version of the MP model that we proposed, a version of the RBC model with such a mechanism can feature a strong propagation of productivity shocks and simultaneously weaker policy effects.

\section{References}

Acemoglu, D. (1999): "Changes in Unemployment and Wage Inequality: An Alternative Theory and Some Evidence," American Economic Review, 89(5).

- (2002): "Directed Technical Change," Review of Economic Studies, 69(4), 781-809. (2007): "Equilibrium Bias of Technology," Econometrica, 75(5), 1371-1409.

Albrecht, J., and S. Vroman (2002): "A Matching Model with Endogenous Skill Requirements," International Economic Review, 43(1), 283-304.

Barron, J. M., M. C. Berger, and D. A. Black (1997): On-the-Job Training. W. E. Upjohn Foundation for Employment Research, Kalamazoo, MI.

Castro, R., and D. Coen-Pirani (2008): "Why Have Aggregate Skilled Hours Become So Cyclical since the Mid-1980s?," International Economic Review, 49(1), 135-184.

Costain, J. S., And M. Reiter (2008): "Business Cycles, Unemployment Insurance, and the Calibration of Matching Models," Journal of Economic Dynamics and Control, 32(4), $1120-1155$. 
Cummins, J., and G. Violante (2002): "Investment-Specific Technical Change in the US (1947-2000): Measurement and Macroeconomic Consequences," Review of Economic Dynamics, 5(2), 243-284.

Fallick, B., and C. A. Fleischman (2004): "Employer-to-Employer Flows in the U.S. Labor Market: The Complete Picture of Gross Worker Flows," Working Paper, Federal Reserve Board of Governors.

Fisher, J. D. M. (2006): "The Dynamic Effects of Neutral and Investment-Specific Technology Shocks," Journal of Political Economy, 114(3), 413-451.

Gordon, R. J. (2007): "Issues in the Comparison of Welfare between Europe and the United States," mimeo, Northwestern University.

Gottschalk, P., and T. M. Smeeding (1997): "Cross-National Comparisons of Earnings and Income Inequality," Journal of Economic Literature, 35, 633-687.

Greenwood, J., Z. Hercowitz, and P. Krusell (1997): "Long-Run Implications of Investment-Specific Technological Change," American Economic Review, 87, 342-362.

Hagedorn, M., F. Karahan, I. Manovskit, and K. Mitman (2013): "Unemployment Benefits and Unemployment in the Great Recession: The Role of Macro Effects," NBER Working Paper 19499, National Bureau of Economic Research, Inc.

Hagedorn, M., and I. Manovskin (2008a): "The Cyclical Behavior of Equilibrium Unemployment and Vacancies Revisited," American Economic Review, 98(4), 1692-1706.

(2008b): "The Cyclical Behavior of Equilibrium Unemployment and Vacancies Revisited," Working Paper 853, European Central Bank.

_ (2011): "Productivity and the Labor Market: Co-Movement over the Business Cycle," International Economic Review, 52(3), 603-619.

(2013): "Job Selection and Wages over the Business Cycle," American Economic Review, 103(2), 771-803.

Hagedorn, M., I. Manovskit, and K. Mitman (2015): "The Impact of Unemployment Benefit Extensions on Employment: The 2014 Employment Miracle?," NBER Working Paper 20884, National Bureau of Economic Research, Inc. 
Hall, R. E. (2005): "Employment Fluctuations with Equilibrium Wage Stickiness," American Economic Review, 95(1), 50-65.

Hall, R. E., And P. R. Milgrom (2008): "The Limited Influence of Unemployment on the Wage Bargain," American Economic Review, 98(4), 1653-1674.

Hansen, G. (1985): "Indivisible Labor and the Business Cycle," Journal of Monetary Economics, 16(3), 309-327.

Hornstein, A., P. Krusell, and G. L. Violante (2005a): "The Effects of Technical Change on Labor Market Inequalities," in Handbook of Economic Growth, ed. by P. Aghion, and S. Durlauf. Elsevier.

(2005b): "Unemployment and Vacancy Fluctuations in the Matching Model: Inspecting the Mechanism," Economic Quarterly (Federal Reserve Bank of Richmond), 91(3), 19-51.

(2007): "Technology-Policy Interaction in Frictional Labour-Markets," Review of Economic Studies, 74(4), 1089-1124.

Keane, M. P., And E. S. Prasad (1991): "The Relation Between Skill Levels and the Cyclical Variability of Employment, Hours and Wages," Discussion paper 41, Federal Reserve Bank of Minneapolis.

Krusell, P., L. E. Ohanian, J.-V. Ríos-Rull, and G. L. Violante (2000): "CapitalSkill Complementarity and Inequality: A Macroeconomic Analysis," Econometrica, 68, 1029-1053.

LuUngqvist, L., And T. J. Sargent (1998): "The European Unemployment Dilemma," Journal of Political Economy, 106(3), 514-550.

(2008): "Two Questions about European Unemployment," Econometrica, 76(1), 129.

Mendoza, E., A. Razin, and L. Tesar (1994): "Effective Tax Rates in Macroeconomics: Cross-country Estimates of Tax Rates on Factor Incomes and Consumption," Journal of Monetary Economics, 34, 297-323.

Michelacci, C., And D. Lopez-Salido (2007): "Technology Shocks and Job Flows," Re- 
view of Economic Studies, 74(4), 1195-1227.

Mortensen, D., and E. Nagypal (2007): "More on Unemployment and Vacancy Fluctuations," Review of Economic Dynamics, 10(3), 327-347.

Mortensen, D., And C. Pissarides (1999): "Unemployment Responses to 'Skill-biased' Technology Shocks: The Role of Labour Market Policy," Economic Journal, 109, 242-265.

Nickell, S., And B. Bell (1996): "Changes in the Distribution of Wages and Unemployment in OECD Countries," American Economic Review, 86(2), 302-308.

Nickell, S., AND R. LAYARD (1999): "Labor market institutions and economic performance," in Handbook of Labor Economics, ed. by O. Ashenfelter, and D. Card, vol. 3 of Handbook of Labor Economics, chap. 46, pp. 3029-3084. Elsevier.

Parker, J. A., And A. Vissing-Jorgensen (2009): "Who Bears Aggregate Fluctuations and How?," American Economic Review, 99(2), 399-405.

Petronglo, B., and C. A. Pissarides (2001): "Looking into the Black Box: A Survey of the Matching Function," Journal of Economic Literature, 39(2), 390-431.

Pissarides, C. A. (1985): "Short-Run Equilibrium Dynamics of Unemployment, Vacancies, and Real Wages," American Economic Review, 75(4), 676-690.

(1998): "The Impact of Employment Tax Cuts on Unemployment and Wages: The Role of Unemployment Benefits and Tax Structure," European Economic Review, 42, 155183.

(2000): Equilibrium Unemployment Theory. MIT Press, Cambridge, MA, second ed. (2009): "The Unemployment Volatility Puzzle: Is Wage Stickiness the Answer?," Econometrica, 77, 1339-1369.

Pissarides, C. A., and G. Vallanti (2007): "The Impact of TFP Growth on Steady-State Unemployment," International Economic Review, 48(2), 607-640.

Prasad, E. S. (1996): "Skill Heterogeneity and the Business Cycle," Canadian Journal of Economics, 29(4), 910-929.

Prescott, E. (1986): "Theory Ahead of Business Cycle Measurement," Federal Reserve Bank of Minneapolis Quarterly Review, 10, 9-22. 
_ (2004): "Why Do Americans Work So Much More Than Europeans," Federal Reserve Bank of Minneapolis Quarterly Review, 28(1), 2-13.

Rogerson, R. (2008): "Structural Transformation and the Deterioration of European Labor Market Outcomes," Journal of Political Economy, 116(2), 235-259.

Rogerson, R., And J. Wallenius (2009): "Micro and Macro Elasticities in a Life Cycle Model with Taxes," Journal of Economic Theory, 144(6), 2277-2292.

Sahin, A., J. Song, G. Topa, And G. L. Violante (2014): "Mismatch Unemployment," American Economic Review, 104(11), 3529-64.

Schmitt, J. (2003): "Creating a Consistent Hourly Wage Series from the Current Population Survey's Outgoing Rotation Group, 1979-2002," Working Paper, Center for Economic and Policy Research.

Schorfheide, F., J.-V. Rios-Rull, C. Fuentes-Albero, R. Santaeulalia-Llopis, And M. KRYshKo (2012): "Methods versus Substance: Measuring the Effects of Technology Shocks," Journal of Monetary Economics, 59(8), 826-846.

SHI, S. (2002): “A Directed Search Model of Inequality with Heterogeneous Skills and SkillBiased Technology," Review of Economic Studies, 69(2), 467-491.

Shimer, R. (2005a): "The Cyclical Behavior of Equilibrium Unemployment and Vacancies," American Economic Review, 95(1), 25-49.

(2005b): "Reassessing the Ins and Outs of Unemployment," mimeo, University of Chicago.

Strauss, H., and C. De la Maisonneive (2007): "The Wage Premium on Tertiary Education: New Estimates for 21 OECD Countries," Working Paper No. 589, OECD Economics Department.

Wong, L. Y. (2003): "Can the Mortensen-Pissarides Model with Productivity Changes Explain U.S. Wage Inequality?," Journal of Labor Economics, 21(1), 70-105. 


\section{APPENDICES}

\section{Data and Variable Construction Procedures}

\section{I.1 Aggregate Data}

Output. Output is BLS non-farm business output. ${ }^{30}$

Employment. Aggregate employment is computed using monthly Current Population Surveys (MCPS) from January 1976 to December 2006. MCPS data are available at http://www.nber.org/data/cps_basic.html. To make this measure of employment consistent with the aggregate measure of output we exclude government, private households and unpaid family workers. We keep government agriculture workers because the CPS did not distinguish between private and government workers in agriculture before July 1985. Since there are only a few government agriculture workers in each sample after June 1985, they do not affect the results. The only inconsistency is that BLS business output does not include the output of non-profit institutions but our measure of employment includes employees of those institutions (because we cannot identify these people in the data). The resulting monthly employment series is seasonally adjusted using the ratio to moving average method and averaged into quarterly series.

Productivity. Aggregate productivity is defined as a ratio of output and employment.

Wages. Aggregate wage series is constructed as BLS labor share in non-farm business sector times productivity.

Capital Structures. We construct quarterly quality-adjusted stock of capital structures using the perpetual inventory method, $k_{s, t+1}=\left(1-d_{s t}\right) k_{s t}+i_{s t}$. Annual series for depreciation of capital structures, $d_{s t}$, for the period from 1947 to 2000 comes from Cummins and Violante (2002). To compute the quarterly series we assume constant depreciation during a year. For the years 2001 through 2006 we assume that $d_{s t}$ is constant and equal to its value in the year 2000. Quality-adjusted investment in structures, $i_{s t}$, is constructed using private fixed

\footnotetext{
${ }^{30} \mathrm{BLS}$ data used are available at http://data.bls.gov/cgi-bin/dsrv?pr.
} 
investment in structures (BEA-NIPA Table 5.3.5) deflated by the price index of non-durables consumption and services, $P C O N S_{t} \cdot{ }^{31} P C O N S_{t}$ is calculated using a Tornqvist procedure. If we have $N$ goods, the change in the price index is

$$
\triangle P C O N S_{t}=\sum_{i=1}^{N} \log \left(\frac{p_{t}^{i}}{p_{t-1}^{i}}\right) \frac{s_{t}^{i}+s_{t-1}^{i}}{2},
$$

and the price index is calculated then recursively

$$
P C O N S_{t}=P C O N S_{t-1} \exp \left(\triangle P C O N S_{t}\right)
$$

where the initial value for the price index is set equal to 1 . The price index for good $i, p_{t}^{i}, i$ $=$ non-durables consumption, services, is taken from BEA-NIPA Table 2.3.4 and the nominal share for good $i, s_{t}^{i}$, is calculated using BEA-NIPA Table 2.3.5. The initial value (year 1947) for the stock of capital structures comes from BEA-FAT Table 2.1. The obtained series is then truncated for the years before 1976.

Capital Equipment. Quarterly quality-adjusted stock of capital equipment is also constructed using the perpetual inventory method, $k_{e, t+1}=\left(1-d_{e t}\right) k_{e t}+i_{e t}$. Annual series for depreciation of capital equipment, $d_{e t}$, is also taken from Cummins and Violante (2002), assuming that $d_{e t}$ is constant during a year and equal to its value in the year 2000 during the period from 2001 to 2006 . We construct the series for nominal investment in equipment as the sum of private fixed investment in equipment (BEA-NIPA Table 5.3.5), changes in inventories (BEA-NIPA Table 1.1.5) and consumer durables (BEA-NIPA Table 1.1.5) and deflate it by the price index for equipment investment, $P E Q_{t}$, to get $i_{e t}$. We use $P E Q_{t}$ series constructed by Schorfheide, Rios-Rull, Fuentes-Albero, Santaeulalia-Llopis, and Kryshko (2012). It is constructed using the annual price index of equipment investment computed by Cummins and Violante (2002) and imputing the quarterly movements of the official NIPA price index of equipment investment. ${ }^{32}$ The initial value $($ year $=1947)$ for the stock of capital equipment comes from BEA-FAT Table 2.1. The obtained series is then truncated for the years before $1976 .^{33}$

\footnotetext{
${ }^{31}$ As a robustness check we computed the price index of non-durables consumption and services excluding energy and housing and did not get any significant changes in the results.

${ }^{32}$ See Schorfheide, Rios-Rull, Fuentes-Albero, Santaeulalia-Llopis, and Kryshko (2012) for details.

${ }^{33}$ As a robustness check we computed the series for the stocks of capital structures and equipment for the period from 1976 to 2006 using 1976 stock as an initial value. There were no important changes in the results.
} 


\section{I.2 Skill-Group Employment and Wages}

The sources of employment and wage data by skill group are monthly Current Population Surveys (MCPS) from January 1976 to December 2006 and CPS Outgoing Rotation Groups (ORG) covering the period January 1979 to December 2006. MCPS data are available at http://www.nber.org/data/cps_basic.html and CPS ORG data are available at http://www.ceprdata.org/cps/org_index.php. To compute the employment series by skill group we use the same procedure as for aggregate employment.

To compute wage series for skilled and unskilled categories we use data constructed by Schmitt (2003) from CPS ORG. Following the approach adopted in Krusell, Ohanian, RíosRull, and Violante (2000) we divide our workers into 198 groups based on their demographic characteristics. There are 11 five-year age groups, 3 race groups (white, black and others), 2 gender groups and 3 education groups (less than high school diploma, high school diploma and college degree and more). Each group, $g$, is defined by age, race, gender and education. The set of groups is denoted by $G$. The measure of the group hourly wage is defined as

$$
w_{g t}=\frac{\sum_{i \in g} w_{i t} h_{i t} \mu_{i t}}{\sum_{i \in g} \mu_{i t}},
$$

where $t=01.1979, \ldots, 12.2006, \mu_{i t}$ - individual's $i$ earnings weight, $h_{i t}$ - individual's $i$ usual weekly hours, $w_{i t}$ - the measure of individual $i$ hourly wage constructed by Schmitt (2003) from CPS ORG. This measure uses a log-normal imputation to adjust for top-coding, trims data below US\$1 and US\$100 per hour (in constant 2002 dollars), includes overtime, tips and commissions for hourly paid workers and imputes usual weekly hours for those who report "hours vary" starting from 1994.

The measure of wages for skilled and unskilled workers in period $t$ is constructed as follows

$$
W_{t}^{j}=\sum_{g \in G_{t}^{j}} w_{g t} \bar{\mu}_{g}^{j}
$$

where $j \in\{u, s\}$ indicates unskilled and skilled type, respectively, $\bar{\mu}_{g}^{j}=\frac{\sum_{t=1}^{T} \mu_{g t}^{j}}{T}$ - temporal average proportion of group $g$ workers in $G^{j}, T$ - number of time periods, $\mu_{g t}^{j}=\frac{\sum_{i \in g} \mu_{i, t}}{\sum_{i \in G_{t}^{j}} \mu_{i, t}}$. The resulting monthly series are deflated using monthly CPI-U, seasonally adjusted using the ratio to moving average method and averaged into quarterly series. 


\section{I.3 Technology Shocks}

The series of investment-specific technology change is calculated as

$$
q_{t}=\frac{P C O N S_{t}}{P E Q_{t}}
$$

To measure neutral technology shocks we use the production function parameters calibrated in Section 3. The monthly skill-group employment series constructed above are seasonally adjusted using the ratio to moving average method and averaged into annual series denoted by $L_{t}$ and $H_{t}$, respectively. Low-skilled labor $l_{t}$ and high-skilled labor $h_{t}$ are normalized as follows

$$
l_{t}=2.6379 * 0.9162 \frac{L_{t}}{\sum_{t=1}^{T} L_{t} / T}, t=1976, . ., 2006
$$

and

$$
h_{t}=0.9737 \frac{H_{t}}{\sum_{t=1}^{T} H_{t} / T}, t=1976, . ., 2006,
$$

where 2.6379 is the measure of low-skilled workers, ${ }^{34}$ and 0.9162 and 0.9737 are employment rates for low-skilled and high-skilled workers, respectively.

The series of neutral technology change is calculated as

$$
A_{t}=\frac{\text { Output }}{k_{s t}^{\alpha}\left[\mu l_{t}^{\sigma}+(1-\mu)\left(\lambda k_{e t}^{\rho}+(1-\lambda) h_{t}^{\rho}\right)^{\frac{\sigma}{\rho}}\right]^{\frac{1-\alpha}{\sigma}}} .
$$

\section{I.4 Job-Finding and Job Separation Probabilities}

To calculate job-finding and job separation probabilities we employ Shimer (2005b) two state approach. Assuming constant labor force,

$$
u_{t+1}=u_{t}\left(1-f_{t}\right)+u_{t+1}^{s}
$$

where $u_{t+1}$ the number of unemployed individuals in month $t, u_{t+1}^{s}$ the number of individuals unemployed for less than one month in month $t$, and $f_{t} \equiv \frac{m(u, v)}{u}$ is a probability that an unemployed individual finds a job. The measure of job separation probability is ${ }^{35}$

$$
s_{t}=\frac{u_{t+1}-\left(1-f_{t}\right) u_{t}}{e_{t}}
$$

\footnotetext{
${ }^{34}$ This number is calculated as the average of $\left\{\frac{L_{t}}{H_{t}}\right\}_{t=01.1976, . ., 12.2006}$. The measure of high-skilled workers is normalized to 1 .

${ }^{35}$ Note that this formula does not take time aggregation into account, since in our model inputs are measured at weekly frequencies.
} 
We use basic monthly CPS data for the number of unemployed individuals and number of people unemployed for less than 4 weeks to construct $f_{t}$ and $s_{f}$ for skilled and unskilled categories.

Until 1994, all unemployed workers were asked about the duration of unemployment. Starting from 1994, the BLS adds the intervening time for unemployed individuals who have been asked about the duration of unemployment in the previous month. To account for this change in methodology we follow the procedure in Shimer (2005b) and multiply all computed series for short-term unemployment by 1.1 after 1994. The resulting monthly series are seasonally adjusted using the ratio to moving average method.

\section{Computation}

We use the free-entry condition (15) and flow equation for the surplus (16) to derive the following difference equations in $\theta^{T}$ :

$$
\frac{c_{x_{t}}^{T}}{\delta \phi^{T}\left(\theta_{x_{t}}^{T}\right)}=E_{x_{t}}\left\{\left(1-\beta^{T}\right)\left(p_{x_{t+1}}^{T}-z^{T}\right)-c_{x_{t}}^{T} \beta^{T} \theta_{x_{t}}^{T}+\frac{\left(1-s^{T}\right) c_{x_{t+1}}^{T}}{\phi^{T}\left(\theta_{x_{t+1}}^{T}\right)}\right\}
$$

We solve this system of difference equations to find $\theta^{T}$ as a function of $x$. Next, we simulate the model to generate artificial time series for neutral and investment-specific shocks, stocks of capital structures and equipment, unemployment, vacancies, and wages for each of the two worker types and the aggregate economy. To do so, we start with an initial value for unemployment of the two groups of workers, as well as neutral and investment-specific productivity shocks. Using the law of motion for employment, we compute next period's employment level $n_{t+1}^{l}=l_{t+1}$ and $n_{t+1}^{h}=h_{t+1}$. Using these numbers compute capital $k_{e, t+1}$ and $k_{s, t+1}$ from the corresponding first-order conditions. Next, we draw a new pair of shocks to productivity and the price of capital equipment according to the stochastic process describing their evolution. We then know $\theta^{T}$ and, thus, the job-finding rate and the new unemployment rate. Iterating this procedure generates the time series of interest.

\section{Theoretical Results}

First some preliminary results: 


\section{Implicit differentiation}

We show how productivity changes in response to changes in $z$, where $p^{l}$ and $p^{h}$ are the fixed point of

$$
\begin{aligned}
& A\left(p^{l}, z^{l}, p^{h}, z^{h}\right)-p^{l}=0, \\
& B\left(p^{l}, z^{l}, p^{h}, z^{h}\right)-p^{h}=0 .
\end{aligned}
$$

It holds that

$$
\left(\begin{array}{cc}
A_{p^{l}}-1 & A_{p^{h}} \\
B_{p^{l}} & B_{p^{h}}-1
\end{array}\right) \cdot\left(\begin{array}{c}
\frac{\partial p^{l}}{\partial z^{l}} \\
\frac{\partial p^{h}}{\partial z^{l}}
\end{array}\right)=\left(\begin{array}{c}
-A_{z^{l}} \\
-B_{z^{l}}
\end{array}\right) .
$$

This implies that

$$
\left(\begin{array}{c}
\frac{\partial p^{l}}{\partial z^{l}} \\
\frac{\partial p^{h}}{\partial z^{l}}
\end{array}\right)=-1 / D D\left(\begin{array}{cc}
B_{p^{h}}-1 & -A_{p^{h}} \\
-B_{p^{l}} & A_{p^{l}}-1
\end{array}\right) \cdot\left(\begin{array}{c}
A_{z^{l}} \\
B_{z^{l}}
\end{array}\right),
$$

where $D D:=\left(1-A_{p^{l}}\right)\left(1-B_{p^{h}}\right)-A_{p^{h}} B_{p^{l}}$. For the derivatives it holds (because equation (33) depends only on $p-z$ ) that

$$
\begin{gathered}
A_{p^{l}}=-A_{z^{l}}, \\
A_{p^{h}}=-A_{z^{h}}, \\
B_{p^{l}}=-B_{z^{l}}, \\
B_{p^{l}}=-B_{z^{l}} .
\end{gathered}
$$

This means that

$$
\begin{aligned}
& \frac{\partial p^{l}}{\partial z^{l}}=\frac{-A_{p^{l}}\left(1-B_{p^{h}}\right)-A_{p^{h}} B_{p^{l}}}{\left(1-A_{p^{l}}\right)\left(1-B_{p^{h}}\right)-A_{p^{h}} B_{p^{l}}}, \\
& \frac{\partial p^{h}}{\partial z^{l}}=\frac{-B_{p^{l}}\left(1-A_{p^{l}}\right)-A_{p^{l}} B_{p^{l}}}{\left(1-A_{p^{l}}\right)\left(1-B_{p^{h}}\right)-A_{p^{h}} B_{p^{l}}} .
\end{aligned}
$$

To simplify this expression, we have to compute $\frac{\partial \pi^{l}}{\partial l}, \frac{\partial \pi^{l}}{\partial h}, \frac{\partial \pi^{h}}{\partial l}$ and $\frac{\partial \pi^{h}}{\partial h}$.

First compute $\frac{\partial \pi^{l}}{\partial l}$ :

$$
\begin{aligned}
\frac{\partial \pi^{l}}{\partial l} & =G_{l k} k_{l}+G_{l l} \\
& =G_{l k} \frac{-G_{l k}}{G_{k k}}+G_{l l} \\
& =G_{l k} \frac{k}{l}+G_{l k} \frac{G_{k h} h}{G_{k k} l}+G_{l l} \\
& =\frac{h}{l}\left(-G_{l h}+G_{k h} \frac{G_{k l}}{G_{k k}}\right),
\end{aligned}
$$


where the first equality follows from implicit differentiation of (32) and the second and third equalities are a consequence of constant returns to scale (which implies that $G_{k}$ and $G_{l}$ are homogeneous of degree zero):

$$
\begin{aligned}
G_{k k} k+G_{k h} h+G_{k l} l & =0, \\
G_{l k} k+G_{l h} h+G_{l l} l & =0 .
\end{aligned}
$$

Now compute $\frac{\partial \pi^{l}}{\partial h}$ :

$$
\begin{aligned}
\frac{\partial \pi^{l}}{\partial h} & =-G_{l k} \frac{G_{k h}}{G_{k k}}+G_{l h} \\
& =-\frac{l}{h} \frac{\partial \pi^{l}}{\partial l} .
\end{aligned}
$$

Making use of similar arguments, it also holds that

$$
\begin{aligned}
\frac{\partial \pi^{h}}{\partial h} & =G_{h k} k_{h}+G_{h h} \\
& =G_{h k} \frac{-G_{h k}}{G_{k k}}+G_{h h} \\
& =G_{h k} \frac{k}{h}+G_{h k} \frac{G_{k l} l}{G_{k k} h}+G_{h h} \\
& =\frac{l}{h}\left(-G_{l h}+G_{k h} \frac{G_{k l}}{G_{k k}}\right)
\end{aligned}
$$

and

$$
\begin{aligned}
\frac{\partial \pi^{h}}{\partial l} & =-G_{h k} \frac{G_{k l}}{G_{k k}}+G_{l h} \\
& =-\frac{h}{l} \frac{\partial \pi^{h}}{\partial h}
\end{aligned}
$$

and

$$
\frac{\partial \pi^{l}}{\partial l}=\frac{h^{2}}{l^{2}} \frac{\partial \pi^{h}}{\partial h}
$$

We can now simplify $\frac{\partial \pi^{l}}{\partial z^{l}}$ and $\frac{\partial \pi^{h}}{\partial z^{l}}$ :

$$
\begin{aligned}
A_{p^{l}} B_{p^{h}}-A_{p^{h}} B_{p^{l}} & =\left(\frac{\partial \pi^{l}}{\partial l} L_{p^{l}}\right)\left(\frac{\partial \pi^{h}}{\partial h} H_{p^{H}}\right)-\left(\frac{\partial \pi^{l}}{\partial h} H_{p^{H}}\right)\left(\frac{\partial \pi^{h}}{\partial l} L_{p^{l}}\right) \\
& =L_{p^{l}} H_{p^{H}}\left(\frac{\partial \pi^{l}}{\partial l} \frac{\partial \pi^{h}}{\partial h}-\left(\frac{-l}{h} \frac{\partial \pi^{l}}{\partial l} \frac{-h}{l} \frac{\partial \pi^{h}}{\partial h}\right)=0\right.
\end{aligned}
$$


and, thus,

$$
\begin{aligned}
\frac{\partial p^{l}}{\partial z^{l}} & =\frac{-A_{p^{l}}}{1-A_{p^{l}}-B_{p^{h}}}, \\
\frac{\partial p^{h}}{\partial z^{l}} & =\frac{-B_{p^{l}}}{1-A_{p^{l}}-B_{p^{h}}} .
\end{aligned}
$$

By the same arguments it follows that

$$
\begin{aligned}
\frac{\partial p^{l}}{\partial z^{h}} & =\frac{-A_{p^{h}}}{1-A_{p^{l}}-B_{p^{h}}}, \\
\frac{\partial p^{h}}{\partial z^{h}} & =\frac{-B_{p^{h}}}{1-A_{p^{l}}-B_{p^{h}}} .
\end{aligned}
$$

\section{III.1 Productivity changes}

To characterize how productivity $\left(p^{l}, p^{h}\right)$ depends on $\left(z^{l}, z^{h}\right)$ requires knowing how the functions $A$ and $B$ depend on productivities $\left(p^{l}, p^{h}\right)$. The next proposition accomplishes this.

\section{Proposition 1}

$$
\begin{aligned}
& \epsilon_{A, p^{l}}=\epsilon_{\pi^{l}, l} \epsilon_{L, p^{l}}=\left\{-\epsilon_{G_{l}, h}+\frac{\epsilon_{G_{k}, h} \cdot \epsilon_{G_{l}, k}}{\epsilon_{G_{k}, k}}\right\} \epsilon_{L, p^{l}}, \\
& \epsilon_{A, p^{h}}=\epsilon_{\pi^{l}, h} \epsilon_{H, p^{l}}=\left\{\epsilon_{G_{l}, h}-\frac{\epsilon_{G_{k}, h} \cdot \epsilon_{G_{l}, k}}{\epsilon_{G_{k}, k}}\right\} \epsilon_{H, p^{l}}, \\
& \epsilon_{B, p^{l}}=\epsilon_{\pi^{h}, l} \epsilon_{L, p^{h}}=\left\{\epsilon_{G_{h}, l}-\frac{\epsilon_{G_{k}, l} \cdot \epsilon_{G_{h}, k}}{\epsilon_{G_{k}, k}}\right\} \epsilon_{L, p^{h}}, \\
& \epsilon_{B, p^{h}}=\epsilon_{\pi^{h}, h} \epsilon_{H, p^{h}}=\left\{-\epsilon_{G_{h}, l}+\frac{\epsilon_{G_{k}, l} \cdot \epsilon_{G_{h}, k}}{\epsilon_{G_{k}, k}}\right\} \epsilon_{H, p^{h}},
\end{aligned}
$$

where $\epsilon_{x, y}$ is the elasticity of $x$ w.r.t. $y$.

\section{Proof of Proposition 1}

Using the above expressions for $\frac{\partial \pi^{l}}{\partial l}, \frac{\partial \pi^{l}}{\partial h}, \frac{\partial \pi^{h}}{\partial l}$ and $\frac{\partial \pi^{h}}{\partial h}$, we find that

$$
\begin{aligned}
\epsilon_{\pi^{l}, l} & =\frac{h}{p^{l}}\left(-G_{l h}+G_{k h} \frac{G_{k l}}{G_{k k}}\right) \\
& =-\epsilon_{G_{l}, h}+\frac{\epsilon_{G_{k}, h} \cdot \epsilon_{G_{l}, k}}{\epsilon_{G_{k}, k}} \\
\epsilon_{\pi^{l}, h} & =\frac{h}{p^{l}}\left(-G_{l h}+G_{k h} \frac{G_{k l}}{G_{k k}}\right) \\
& =-\epsilon_{\pi^{l}, l}
\end{aligned}
$$




$$
\begin{aligned}
\epsilon_{\pi^{h}, h} & =\frac{l}{p^{h}}\left(-G_{l h}+G_{k h} \frac{G_{k l}}{G_{k k}}\right) \\
& =-\epsilon_{G_{h}, l}+\frac{\epsilon_{G_{k}, l} \cdot \epsilon_{G_{h}, k}}{\epsilon_{G_{k}, k}} \\
& =\frac{l p^{l}}{h p^{h}} \epsilon_{\pi^{l}, l} \\
\epsilon_{\pi^{h}, l} & =-G_{h k} \frac{G_{k l}}{G_{k k}}+G_{l h} \\
& =-\epsilon_{\pi^{h}, h}
\end{aligned}
$$

From the definitions of the functions $A, B, \pi^{l}$ and $\pi^{h}$ it follows that

$$
\begin{aligned}
\epsilon_{A, p^{l}} & =\epsilon_{\pi^{l}, l} \epsilon_{L, p^{l}}, \\
\epsilon_{A, p^{h}} & =\epsilon_{\pi^{l}, h} \epsilon_{H, p^{l}}, \\
\epsilon_{B, p^{l}} & =\epsilon_{\pi^{h}, l} \epsilon_{L, p^{h}}, \\
\epsilon_{B, p^{h}} & =\epsilon_{\pi^{h}, h} \epsilon_{H, p^{h}},
\end{aligned}
$$

which proves the proposition.

We can consider two special cases in which productivity is invariant when policy is changed. The first case arises if the two types of workers are perfect substitutes, so that the production part of the model is equivalent to a model with homogeneous workers. In this case the invariance of productivity is not very surprising. Any drop in labor leads to a drop in capital, such that the capital-labor ratio remains unchanged. Since labor productivity is a function of the capital-labor ratio, it does not change either.

The assumption that the two labor inputs are perfect substitutes implies that $G_{l l}=G_{h h}=$ $G_{l h}$ and that $G_{k l}=G_{k h}$ and it implies the following proposition:

Proposition 2 (Special Case: $\mathbf{L}$ and $\mathbf{H}$ are Perfect Substitutes) If the two labor inputs $l$ and $h$ are perfect substitutes, then the labor productivities do not change with changes in labor inputs: $\epsilon_{\pi^{l}, l}=\epsilon_{\pi^{h}, h}=\epsilon_{\pi^{l}, h}=\epsilon_{\pi^{l}, h}=0$.

\section{Proof of Proposition 2}

CRS and perfect substitutes imply that

$$
\begin{aligned}
G_{k k} k+G_{k h} h+G_{k l} l & =G_{k k} k+G_{k l}(h+l)=0, \\
G_{l k} k+G_{l h} h+G_{k k} l & =G_{l k} k+G_{l l}(h+l)=0 .
\end{aligned}
$$


The first equation implies that

$$
(h+l)=-\frac{G_{k l}}{G_{k k}} k .
$$

Plugging this into the second equation implies that

$$
G_{l k} k+G_{l l}-\frac{G_{k l}}{G_{k k}} k=0 .
$$

This implies that

$$
\begin{aligned}
\epsilon_{\pi^{l}, l} & =\frac{h}{p^{l}}\left(-G_{l h}+G_{k h} \frac{G_{k l}}{G_{k k}}\right) \\
& =\frac{h}{p^{l}}\left(-G_{l l}+G_{k l} \frac{G_{k l}}{G_{k k}}\right)=0 .
\end{aligned}
$$

Noting that all of the four elasticities are just a multiple of each other concludes the proof.

A similar logic applies when one of the two labor inputs is unrelated to the other labor input and capital, that is, either $G_{l h}=0$ and $G_{k l}=0$ or $G_{l h}=0$ and $G_{k h}=0$. In each of these two cases, the economy consists of two unrelated economies, each of which has only one type of worker. Since "both economies" have a CRS production function with a representative agent, the previous proposition applies.

Proposition 3 (Special Case: $\mathbf{L}$ and $\mathbf{H}$ are Unrelated Inputs) If either $G_{l h}=0$ and $G_{k l}=0$ or $G_{l h}=0$ and $G_{k h}=0$, then productivity remains unchanged: $\epsilon_{\pi^{l}, l}=\epsilon_{\pi^{h}, h}=\epsilon_{\pi^{l}, h}=$ $\epsilon_{\pi^{l}, h}=0$.

\section{Proof of Proposition 3}

Follows directly from inspection of $\frac{\partial \pi^{l}}{\partial l}$.

The production function we use in this paper does not fall into one of the two special cases. Instead it implies the following assumption:

Assumption $1 G_{l h} \geq 0$ and $G_{k l} G_{k h} \geq 0$, where at least one inequality is strict.

With this assumption, we can show that productivity indeed changes when the policy parameter $z$ is changed and we know the sign of this change. The key step is to show that labor productivity changes if the amount of labor input is changed. The reason why these changes are not zero is that the above logic does not fully apply anymore. With a representative agent, a fully flexible capital stock adjusts to keep the capital-labor ratio and thus labor productivity 
constant. If, instead, capital was fixed or not fully flexible, labor productivity would increase in response to a decrease in labor. With two types of labor a similar effect obtains. Capital cannot fully adjust to keep the two capital-labor ratios constant. Instead, there is only partial adjustment, as would be the case with a representative agent if the capital stock is a fixed factor. As a consequence, labor productivity is not constant. The next proposition states this and also establishes how the functions $A$ and $B$ respond to changes in $p^{l}$ and $p^{h}$.

Proposition 4 If assumption 1 holds, then

$$
\begin{aligned}
& \epsilon_{\pi^{l}, l}, \epsilon_{\pi^{h}, h}, A_{p^{l}}, B_{p^{h}}<0, \\
& \epsilon_{\pi^{l}, h}, \epsilon_{\pi^{h}, l}, A_{p^{h}}, B_{p^{l}}>0,
\end{aligned}
$$

\section{Proof of Proposition 4}

Follows directly from Assumption 1 and Proposition 1.

Once the signs of the derivatives of the functions $A$ and $B$ are known, the last step is easy:

\section{Proposition 5}

$$
\begin{aligned}
\frac{\partial p^{l}}{\partial z^{l}} & =\frac{-A_{p^{l}}}{1-A_{p^{l}}-B_{p^{h}}}>0, \\
\frac{\partial p^{h}}{\partial z^{l}} & =\frac{-B_{p^{l}}}{1-A_{p^{l}}-B_{p^{h}}}<0, \\
\frac{\partial p^{l}}{\partial z^{h}} & =\frac{-A_{p^{h}}}{1-A_{p^{l}}-B_{p^{h}}}<0, \\
\frac{\partial p^{h}}{\partial z^{h}} & =\frac{-B_{p^{h}}}{1-A_{p^{l}}-B_{p^{h}}}>0 .
\end{aligned}
$$

It also holds that $\frac{\partial p^{l}}{\partial z^{l}}<1$ and $\frac{\partial p^{h}}{\partial z^{h}}<1$, so that $\frac{\partial\left(p^{l}-z^{l}\right)}{\partial z^{l}}<0$ and $\frac{\partial\left(p^{h}-z^{h}\right)}{\partial z^{h}}<0$.

\section{Proof of Proposition 5}

How the derivatives of $p$ with respect to $z$ are related to the derivatives of $A$ and $B$ was shown above. The sign of these derivatives then follows immediately from Proposition 3.

\section{III.2 What does this mean for employment changes?}

Once the change in productivity is known, it is sufficient to look at equations (35) and (36) to figure out the change in employment. For example, if $p-z$ increases, employment increases, 
and if $p-z$ decreases, employment decreases.

More generally, the change in total employment $l+h$ in response to a change in $z^{l}$ is:

$$
\begin{aligned}
\epsilon_{l+h, z^{l}} & =\left(\left(L_{p^{l}} \frac{\partial p^{l}}{\partial z^{l}}+L_{z^{l}}\right)+H_{p^{h}} \frac{\partial p^{h}}{\partial z^{l}}\right) \frac{z^{l}}{l+h} \\
& =\left(\epsilon_{L, p^{l}} \epsilon_{p^{l}, z^{l}}+\epsilon_{L, z^{l}}\right) \frac{l}{l+h}+\epsilon_{H, p^{h}} \epsilon_{p^{h}, z^{l}} \frac{h}{l+h},
\end{aligned}
$$

which means that the total employment change is a weighted sum of the change in $l$ and in $h$. Similarly, the change in total employment in response to a change in $z^{h}$ is:

$$
\begin{aligned}
\epsilon_{l+h, z^{h}} & =\left(\left(H_{p^{h}} \frac{\partial p^{h}}{\partial z^{h}}+H_{z^{h}}\right)+L_{p^{l}} \frac{\partial p^{l}}{\partial z^{h}}\right) \frac{z^{h}}{l+h} \\
& =\left(\epsilon_{H, p^{h}} \epsilon_{p^{h}, z^{h}}+\epsilon_{H, z^{h}}\right) \frac{h}{l+h}+\epsilon_{L, p^{l}} \epsilon_{p^{l}, z^{h}} \frac{l}{l+h} .
\end{aligned}
$$

The total change, if $z^{l}$ and $z^{h}$ go up by $1 \%$ equals

$$
\epsilon_{l+h, z^{l}}+\epsilon_{l+h, z^{h}}
$$

This expression equals

$$
\begin{aligned}
& \epsilon_{l+h, z^{l}}+\epsilon_{l+h, z^{h}}= \\
& \frac{l}{l+h}\left(\epsilon_{L, p^{l}}\left(\epsilon_{p^{l}, z^{h}}+\epsilon_{p^{l}, z^{l}}\right)+\epsilon_{L, z^{l}}\right)+\frac{h}{l+h}\left(\epsilon_{H, p^{h}}\left(\epsilon_{p^{h}, z^{l}}+\epsilon_{p^{h}, z^{h}}\right)+\epsilon_{H, z^{h}}\right) \\
& \frac{l}{l+h}\left(\frac{\epsilon_{L, p^{l}}}{\vartheta}\left(\epsilon_{\pi^{l}, h} \epsilon_{H, z^{h}}+\epsilon_{\pi^{l}, l} \epsilon_{L, z^{l}}\right)+\epsilon_{L, z^{l}}\right)+\frac{h}{l+h}\left(\frac{\epsilon_{H, p^{h}}}{\vartheta}\left(\epsilon_{\pi^{h}, l} \epsilon_{L, z^{l}}+\epsilon_{\pi^{h}, h} \epsilon_{H, z^{h}}\right)+\epsilon_{H, z^{h}}\right) \\
& \frac{l}{l+h}\left(\epsilon_{L, p^{l}}\left(\frac{\epsilon_{\pi^{l}, l}}{\vartheta}\left(\epsilon_{L, z^{l}}-\epsilon_{H, z^{h}}\right)+\epsilon_{L, z^{l}}\right)+\frac{h}{l+h}\left(\epsilon_{H, p^{h}}\left(\frac{\epsilon_{\pi^{h}, h}}{\vartheta}\left(\epsilon_{H, z^{h}}-\epsilon_{L, z^{l}}\right)+\epsilon_{H, z^{h}}\right),\right.\right.
\end{aligned}
$$

where $\vartheta=1-A_{p^{l}}-B_{p^{h}}$, which is positive under Assumption 1 (as established in Proposition 4). This expression is quite insightful. The change in $l$-productivity $p^{l}$ due to a change in $z$ equals $\frac{1}{\vartheta}\left(\epsilon_{\pi^{l}, h} \epsilon_{H, z^{h}}+\epsilon_{\pi^{l}, l} \epsilon_{L, z^{l}}\right)$ and similarly the change of the $h$-productivity $p^{h}$ equals $\frac{1}{\vartheta}\left(\epsilon_{\pi^{h}, l} \epsilon_{L, z^{l}}+\epsilon_{\pi^{h}, h} \epsilon_{H, z^{h}}\right)$. If these changes are zero, this means productivity is constant, and the change in employment would equal

$$
\frac{l}{l+h} \epsilon_{L, z^{l}}+\frac{h}{l+h} \epsilon_{H, z^{h}}
$$

which is a weighted sum of the changes in $l$ and in $h$. This composition effect strictly dampens the change in employment (and thus unemployment) relative to the group effects, whenever one group is more responsive to policy than the other group, for example, if $\left|\epsilon_{L, z^{l}}\right|>\left|\epsilon_{H, z^{h}}\right|$. 
If, however, productivity responds to changes in $z$, the response of group employment changes. If productivity increases in response to an increase in $z$, the employment effect is mitigated ( $p-z$ decreases by less); if productivity decreases in response to an increase in $z$, the employment effect is amplified ( $p-z$ decreases by more).

Whether productivity increases or decreases for group $l$ and group $h$ is described by the signs of $\frac{\epsilon_{\pi^{l}, l},}{\vartheta}\left(\epsilon_{L, z^{l}}-\epsilon_{H, z^{h}}\right)$ and of $\frac{\epsilon_{\pi^{h}, h}}{\vartheta}\left(\epsilon_{H, z^{h}}-\epsilon_{L, z^{l}}\right)$. Multiplying these expressions with $\epsilon_{L, p^{l}}$ and $\epsilon_{H, p^{h}}$, respectively, translates the productivity changes into employment changes (higher productivity leads to higher employment).

One implication of the above expression is that the change in employment is equal to that with constant productivity if $\epsilon_{L, z^{l}}-\epsilon_{H, z^{h}}=0$ (both types of labor respond in the same way to changes in unemployment insurance), namely,

Proposition 6 If $\epsilon_{L, z^{l}}-\epsilon_{H, z^{h}}=0$, then productivity does not change and the change in total employment equals

$$
\epsilon_{l+h, z^{l}}+\epsilon_{l+h, z^{h}}=\frac{l}{l+h} \epsilon_{L, z^{l}}+\frac{h}{l+h} \epsilon_{H, z^{h}}
$$

because in this case productivity would not move (endogenously).

Furthermore, it follows that if one group has a stronger labor demand elasticity, for example, group $L\left(\epsilon_{L, z^{l}}-\epsilon_{H, z^{h}}<0\right)$, then the productivity of this group increases and the drop in employment is mitigated, whereas the productivity of the other group decreases (since $\left.\epsilon_{L, p^{l}}>0, \epsilon_{p^{l}, L}<0, \epsilon_{H, p^{h}}>0, \epsilon_{p^{h}, H}<0\right)$.

Proposition 7 If $\epsilon_{L, z^{l}}-\epsilon_{H, z^{h}}<0$, then $p^{l}$ increases and $p^{h}$ decreases. As a consequence the employment response of group $l$ is mitigated (relative to constant productivity) and the employment response of group $h$ is amplified (relative to constant productivity).

The overall effect on employment due to the change in productivity would be (since $\epsilon_{p^{h}, H}=$ $\left.\frac{l p^{l}}{h p^{h}} \epsilon_{p^{l}, L}\right)$

$$
\begin{aligned}
& \frac{l}{l+h}\left(\epsilon_{L, p^{l}}\left(\frac{\epsilon_{\pi^{l}, l}}{\vartheta}\left(\epsilon_{L, z^{l}}-\epsilon_{H, z^{h}}\right)\right)+\frac{h}{l+h}\left(\epsilon_{H, p^{h}}\left(\frac{\epsilon_{\pi^{h}, h}}{\vartheta}\left(\epsilon_{H, z^{h}}-\epsilon_{L, z^{l}}\right)\right)\right.\right. \\
& =\frac{l}{l+h} \frac{\epsilon_{\pi^{l}, l}}{\vartheta}\left(\epsilon_{L, z^{l}}-\epsilon_{H, z^{h}}\right)\left(\epsilon_{L, p^{l}}-\frac{p^{l}}{p^{h}} \epsilon_{H, p^{h}}\right),
\end{aligned}
$$

which is positive if $\frac{p^{l}}{p^{h}}$ is not substantially larger than one (if group $h$ are high-skilled workers with lower relative $z$ and higher productivity, this conclusion obviously holds). 
Proposition 8 The overall effect on employment due to the change in productivity equals

$$
\frac{l}{l+h} \frac{\epsilon_{\pi^{l}, l}}{\vartheta}\left(\epsilon_{L, z^{l}}-\epsilon_{H, z^{h}}\right)\left(\epsilon_{L, p^{l}}-\frac{p^{l}}{p^{h}} \epsilon_{H, p^{h}}\right),
$$

which is positive if $\frac{p^{l}}{p^{h}}$ is not substantially larger than one.

\section{III.3 Comparative statics}

Consider the impact of different parameter values on the overall effect on employment in equation (A52).

Proposition 9 Consider the employment effect due to productivity changes:

- Skill premium: A decrease in $\frac{p^{l}}{p^{h}}$ increases the effect if $\epsilon_{L, z^{l}}-\epsilon_{H, z^{h}}>0$.

- Preferences: An increase in $\epsilon_{L, z^{l}}-\epsilon_{H, z^{h}}(>0)$ (for example if $z^{l}-z^{h}$ increases) increases the effect.

- Production: Any change in the production function that lowers $\epsilon_{\pi^{l}, l}<0$ increases the effect. This would happen if one of the positive values $G_{l h}, G_{l k}, G_{h k}$ increases. 


\section{Tax Policy and the value of Non-market Activity}

Our focus in this paper was to understand the role of heterogeneity and imperfect substitutability of factors in the production function on the dampening of the labor market effects of economic policies. Of course, there are numerous other economic mechanisms that can work towards that goal. We discussed some of them in Section 5.2 in the main text. In this appendix we draw on Hagedorn and Manovskii (2008b) and illustrate another particularly simple mechanism based on the long-run response of the value of non-market activity induced by changes in policies. ${ }^{36}$

It is plausible that the flow utility form unemployment may depend on the length of the unemployment spell, as illustrated in the top panel of Figure A-1. For example, the longterm unemployed may face problems replacing their durable consumption goods (a broken TV, dishwasher, microwave, etc.). Furthermore, having a month off to enjoy leisure has a high value, but the enjoyment of a year of unemployment is questionable. In our benchmark calibration we (implicitly) estimate the average $z^{T}$ of all unemployed in a respective skill group. Given the relatively high job finding rates in the US data, short-term unemployed make up the bulk of observations. Thus, our estimates of $z^{T}$ represent the value of non-market activity for the average unemployed, who finds employment quickly.

Allowing $z$ to decrease with the length of the unemployment spell makes $z$ endogenous. When productivity declines, the average duration of unemployment increases and thus the average $z$ of the unemployment pool declines as well. This is unlikely, however, to dampen the models ability to replicate business cycle facts. It creates some procyclicality in $z$, but our calibration strategy would then reduce the bargaining power to match the cyclicality of wages. Since the effects of productivity shocks over the business cycle are relatively short-lived, the average duration of unemployment and, thus, the average $z$ are unlikely to change much over the business cycle.

However, the presence of curvature in the value of non-market activity likely dampens the effects of policies. Consider a change in policy, such as an increase in tax rates or unemployment benefits, that increases $z$ relative to $p$. A stylized illustration of the effects is illustrated in

\footnotetext{
${ }^{36}$ Our discussion here is reduced form. This is intentional. The structural model of the evolution of $z$ and its identification are too complex to be adequately developed in this paper
} 

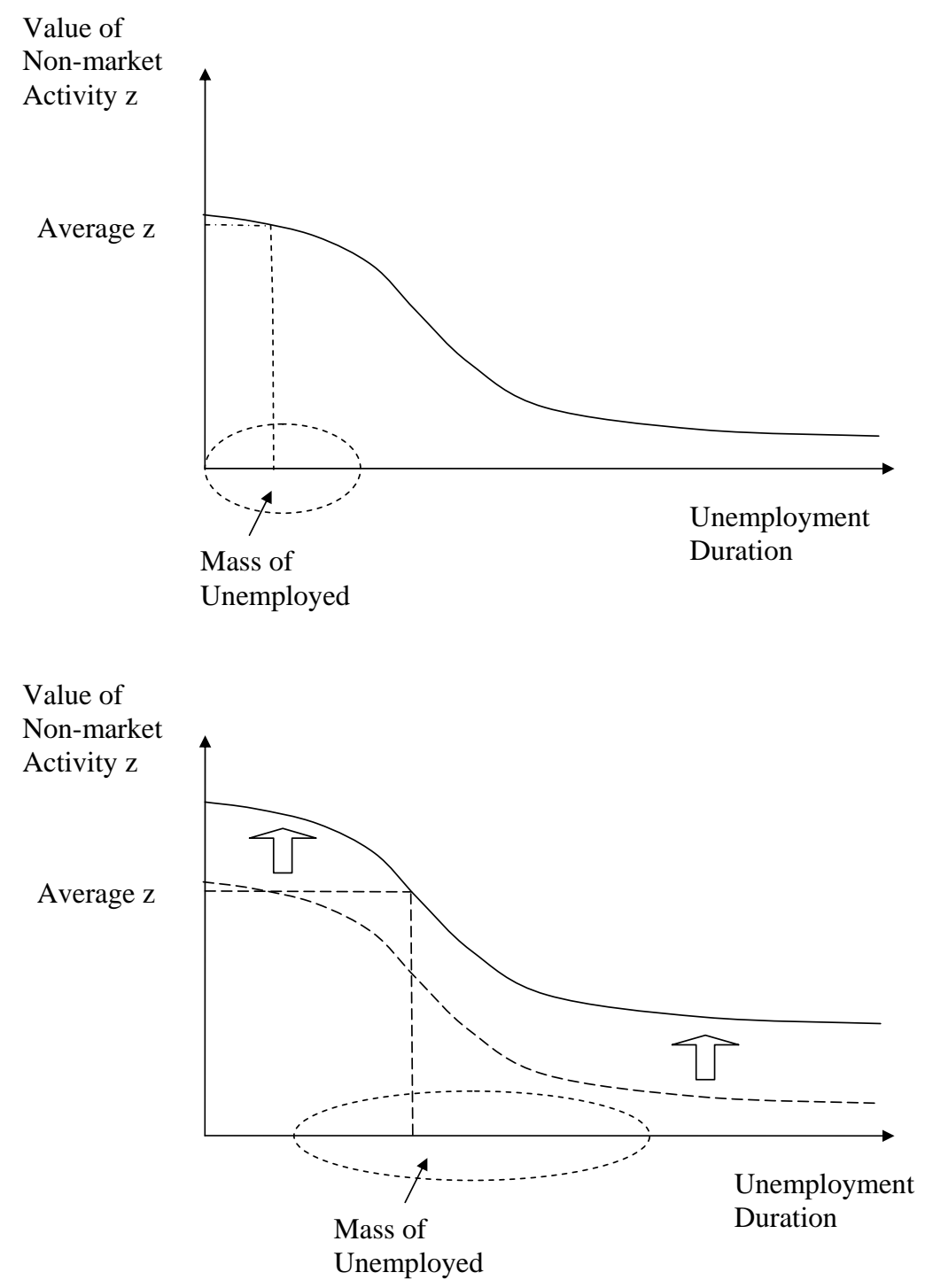

Figure A-1: Effect of policies with endogenous $z$.

the bottom panel of Figure A-1. In response to such a policy firms post fewer vacancies. This leads to an increase in the average duration of unemployment accompanied by a decline in the average $z$ of the unemployment pool. This works against the direct effect of the policy and moves the economy closer to the equilibrium prior to the change in the policy (towards restoring the gap between $p$ and $z$ ). Thus, depending on the curvature of $z$, the effects of persistent changes in policy may be entirely canceled out. 


\section{Appendix Tables}

Table A-1: Matching the Calibration Targets with Low Wage Elasticity.

\begin{tabular}{llcc}
\hline \multicolumn{2}{c}{ Target } & \multicolumn{2}{c}{ Value } \\
\hline & & Data & Model \\
\cline { 3 - 4 } 1. & Elasticity of wages wrt agg. productivity, $\epsilon_{w, p}$ & 0.500 & 0.498 \\
2. & Relative elasticity of wages wrt agg. productivity, $\epsilon_{w^{H}, p} / \epsilon_{w^{L}, p}$ & 1.770 & 1.775 \\
3. & Skilled job-finding rate, $f^{H}$ & 0.106 & 0.105 \\
4. & Unskilled job-finding rate, $f^{L}$ & 0.127 & 0.126 \\
5. & Skilled average market tightness, $\theta^{H}$ & 1.044 & 1.039 \\
6. & Unskilled average market tightness, $\theta^{L}$ & 0.586 & 0.584 \\
7. & Elasticity of agg. job-finding wrt agg. market tightness, $\epsilon_{f, \theta}$ & 0.500 & 0.497 \\
8. & Relative elas. of job-finding wrt agg. mrkt tightness, $\epsilon_{f^{H}, \theta} / \epsilon_{f^{L}, \theta}, \theta$ & 1.335 & 1.335 \\
9. & Standard deviation of capital structures & 0.003 & 0.003 \\
10. & Standard deviation of capital equipment & 0.010 & 0.010 \\
\hline
\end{tabular}

Note - The table describes the model's performance in matching the calibration targets, including low wage elasticity. 
Table A-2: Calibrated Parameter Values with Low Wage Elasticity.

\begin{tabular}{lll}
\hline Parameter & Definition & Value \\
\hline$z^{H}$ & skilled value of non-market activity (share of their productivity) & 0.848 \\
$z^{L}$ & unskilled value of non-market activity (share of their productivity) & 0.945 \\
$\beta^{H}$ & skilled workers' bargaining power & 0.043 \\
$\beta^{L}$ & unskilled workers' bargaining power & 0.072 \\
$\gamma^{H}$ & skilled matching function elasticity & 0.238 \\
$\gamma^{L}$ & unskilled matching function elasticity & 0.544 \\
$\chi^{H}$ & skilled matching function efficiency & 0.104 \\
$\chi^{L}$ & unskilled matching function efficiency & 0.165 \\
$d_{s}^{*}$ & depreciation factor of capital structures & 11.800 \\
$d_{e}^{*}$ & depreciation factor of capital equipment & 1.460 \\
\hline
\end{tabular}

Note - The table contains the calibrated parameter values in the low wage elasticity calibration. 
Table A-3: Results from the Calibrated Model with Low Wage Elasticity.

\begin{tabular}{|c|c|c|c|c|}
\hline & \multirow[t]{2}{*}{ Statistic } & \multicolumn{3}{|c|}{ Value } \\
\hline & & $\begin{array}{c}\text { Data, } 1951-2004 \\
\text { (1) }\end{array}$ & $\begin{array}{c}\text { Model } \\
(2)\end{array}$ & $\begin{array}{l}\text { LM } \\
(3)\end{array}$ \\
\hline 1. & St. dev. of agg. productivity, $p$ & 0.013 & 0.013 & 0.013 \\
\hline 2 . & Autocorr. of agg. productivity, $p$ & 0.765 & 0.765 & 0.765 \\
\hline 3. & St. dev. of agg. unemployment, $u$ & 0.125 & 0.104 & 0.071 \\
\hline 4 . & St. dev. of agg. vacancies, $v$ & 0.139 & 0.142 & 0.101 \\
\hline 5. & St. dev. of agg. market tightness, $\theta$ & 0.259 & 0.246 & 0.163 \\
\hline 6 . & Corr. of agg. unemployment and vacancies & -0.919 & -0.782 & -0.780 \\
\hline 1. & St. dev. of skilled productivity, $p^{H}$ & - & 0.018 & - \\
\hline 2. & Autocorr. of skilled productivity, $p^{H}$ & - & 0.779 & - \\
\hline 3. & St. dev. of skilled unemployment, $u^{H}$ & - & 0.138 & - \\
\hline 4 . & St. dev. of skilled vacancies, $v^{H}$ & - & 0.103 & - \\
\hline 5. & St. dev. of skilled market tightness, $\theta^{H}$ & - & 0.207 & - \\
\hline 1. & St. dev. of unskilled productivity, $p^{L}$ & - & 0.013 & - \\
\hline 2. & Autocorr. of unskilled productivity, $p^{L}$ & - & 0.754 & - \\
\hline 3. & St. dev. of unskilled unemployment, $u^{L}$ & - & 0.100 & - \\
\hline 4. & St. dev. of unskilled vacancies, $v^{L}$ & - & 0.170 & - \\
\hline 5. & St. dev. of unskilled market tightness, $\theta^{L}$ & - & 0.258 & - \\
\hline
\end{tabular}

Note - Column (1) contains aggregate statistics computed over the 1951:1 to 2004:4 period as in Shimer (2005a). Hornstein, Krusell, and Violante (2005b) report virtually identical numbers. In Column (1) seasonally adjusted unemployment, $u$, is constructed by the Bureau of Labor Statistics (BLS) from the Current Population Survey (CPS). The seasonally adjusted help-wanted advertising index, $v$, is constructed by the Conference Board. Both $u$ and $v$ are quarterly averages of monthly series. Average labor productivity $p$ is seasonally adjusted real average output per person in the non-farm business sector, constructed by the BLS from the National Income and Product Accounts and the Current Employment Statistics. Column (2) contains the results from the model calibrated with low wage elasticity. Column (3) reproduces the results from the linear model with homogeneous workers for the same aggregate calibration targets. All variables are reported in logs as deviations from an HP trend with smoothing parameter 1600 . 
Table A-4: Matching the Calibration Targets with $s=s_{U}$.

\begin{tabular}{llll}
\hline & Target & \multicolumn{2}{c}{ Value } \\
\hline & & Data & Model \\
1. & Elasticity of wages wrt agg. productivity, $\epsilon_{w, p}$ & 0.670 & 0.669 \\
2. & Relative elasticity of wages wrt agg. productivity, $\epsilon_{w^{H}, p} / \epsilon_{w^{L}, p}$ & 1.770 & 1.801 \\
3. & Skilled job-finding rate, $f^{H}$ & 0.106 & 0.105 \\
4. & Unskilled job-finding rate, $f^{L}$ & 0.127 & 0.127 \\
5. & Skilled average market tightness, $\theta^{H}$ & 1.044 & 1.059 \\
6. & Unskilled average market tightness, $\theta^{L}$ & 0.586 & 0.604 \\
7. & Elasticity of agg. job-finding wrt agg. market tightness, $\epsilon_{f, \theta}$ & 0.500 & 0.501 \\
8. & Relative elas. of job-finding wrt agg. mrkt tightness, $\epsilon_{f^{H}, \theta} / \epsilon_{f^{L}, \theta}$ & 1.335 & 1.346 \\
9. & Standard deviation of capital structures & 0.003 & 0.003 \\
10. & Standard deviation of capital equipment & 0.010 & 0.010 \\
\hline
\end{tabular}

Note - The table describes the model's performance in matching the calibration targets without distinguishing between the total separation rate and the separation rate into unemployment.

Table A-5: Calibrated Parameter Values with $s=s_{U}$.

\begin{tabular}{lll}
\hline Parameter & Definition & Value \\
\hline$z^{H}$ & skilled value of non-market activity (share of their productivity) & 0.897 \\
$z^{L}$ & unskilled value of non-market activity (share of their productivity) & 0.943 \\
$\beta^{H}$ & skilled workers' bargaining power & 0.064 \\
$\beta^{L}$ & unskilled workers' bargaining power & 0.098 \\
$\gamma^{H}$ & skilled matching function elasticity & 0.230 \\
$\gamma^{L}$ & unskilled matching function elasticity & 0.540 \\
$\chi^{H}$ & skilled matching function efficiency & 0.102 \\
$\chi^{L}$ & unskilled matching function efficiency & 0.164 \\
$d_{s}^{*}$ & depreciation factor of capital structures & 11.500 \\
$d_{e}^{*}$ & depreciation factor of capital equipment & 1.420 \\
\hline
\end{tabular}

Note - The table contains the calibrated parameter values in the calibration without distinguishing between the total separation rate and the separation rate into unemployment. 
Table A-6: Results from the Calibrated Model with $s=s_{U}$.

\begin{tabular}{|c|c|c|c|c|}
\hline & \multirow[t]{2}{*}{ Statistic } & \multicolumn{3}{|c|}{ Value } \\
\hline & & Data & Model & $\mathrm{LM}$ \\
\hline & & $(1)$ & $(2)$ & $(3)$ \\
\hline 1. & St. dev. of agg. productivity, $p$ & 0.013 & 0.013 & 0.013 \\
\hline 2. & Autocorr. of agg. productivity, $p$ & 0.765 & 0.765 & 0.765 \\
\hline 3. & St. dev. of agg. unemployment, $u$ & 0.090 & 0.096 & 0.061 \\
\hline 4. & St. dev. of agg. vacancies, $v$ & 0.116 & 0.130 & 0.086 \\
\hline 5 . & St. dev. of agg. market tightness, $\theta$ & 0.202 & 0.227 & 0.139 \\
\hline 6. & Corr. of agg. unemployment and vacancies & -0.910 & -0.780 & -0.780 \\
\hline 1. & St. dev. of skilled productivity, $p^{H}$ & - & 0.018 & - \\
\hline 2. & Autocorr. of skilled productivity, $p^{H}$ & - & 0.778 & - \\
\hline 3. & St. dev. of skilled unemployment, $u^{H}$ & 0.111 & 0.129 & - \\
\hline 4. & St. dev. of skilled vacancies, $v^{H}$ & - & 0.096 & - \\
\hline 5. & St. dev. of skilled market tightness, $\theta^{H}$ & - & 0.192 & - \\
\hline 1. & St. dev. of unskilled productivity, $p^{L}$ & - & 0.013 & - \\
\hline 2. & Autocorr. of unskilled productivity, $p^{L}$ & - & 0.758 & - \\
\hline 3. & St. dev. of unskilled unemployment, $u^{L}$ & 0.085 & 0.093 & - \\
\hline 4. & St. dev. of unskilled vacancies, $v^{L}$ & - & 0.156 & - \\
\hline 5 . & St. dev. of unskilled market tightness, $\theta^{L}$ & - & 0.238 & - \\
\hline
\end{tabular}

Note - Column (1) reproduces Column (1) of Table 3. See notes to that table for details. Column (2) contains the results from the model calibrated without distinguishing between the total separation rate and the separation rate into unemployment. Column (3) shows the results from the linear model with homogeneous workers for the same aggregate calibration targets. All variables are reported in logs as deviations from an HP trend with smoothing parameter 1600. 